Florida International University FIU Digital Commons

3-30-2017

\title{
Prevalence and Determinants of Overweight and Obesity in Preschoolers in Miami-Dade County
}

Catherina Chang

Florida International University, cchan008@fiu.edu

DOI: 10.25148 /etd.FIDC001805

Follow this and additional works at: https://digitalcommons.fiu.edu/etd

Part of the Community Health and Preventive Medicine Commons, Epidemiology Commons, and the Maternal and Child Health Commons

\section{Recommended Citation}

Chang, Catherina, "Prevalence and Determinants of Overweight and Obesity in Preschoolers in Miami-Dade County" (2017). FIU Electronic Theses and Dissertations. 3171.

https://digitalcommons.fiu.edu/etd/3171 


\title{
FLORIDA INTERNATIONAL UNIVERSITY
}

Miami, Florida

\section{PREVALENCE AND DETERMINANTS OF OVERWEIGHT AND OBESITY \\ IN PRESCHOOLERS IN MIAMI-DADE COUNTY}

\author{
A dissertation submitted in partial fulfillment of the \\ requirements for the degree of \\ DOCTOR OF PHILOSOPHY
}

In

PUBLIC HEALTH

by

Catherina Chang Martinez

2017 
To: Dean Tomás R. Guilarte

Robert Stempel College of Public Health and Social Work

This dissertation, written by Catherina Chang Martinez, and entitled Prevalence and Determinants of Overweight and Obesity in Preschoolers in Miami-Dade County, having been approved in respect to style and intellectual content, is referred to you for judgment.

We have read this dissertation and recommend that it be approved.

$\begin{array}{r}\hline \text { Wasim Maziak } \\ \hline \text { Ruby A. Natale } \\ \hline \text { Vukosava Pekovic } \\ \hline \text { Emir Veledar }\end{array}$

Nasar U. Ahmed, Major Professor

Date of Defense: March 30, 2017

The dissertation of Catherina Chang Martinez is approved.

Dean Tomás R. Guilarte Robert Stempel College of Public Health and Social Work

Andrés G. Gil Vice President for Research and Economic Development and Dean of the University Graduate School

Florida International University, 2017 
(c) Copyright 2017 by Catherina Chang Martinez

All rights reserved. 


\section{DEDICATION}

I dedicate this dissertation to my parents, husband, and children for their patience, support, understanding, and love in the completion of this journey. 


\section{ACKNOWLEDGMENTS}

I would like to thank my family for their support through this academic journey. I am grateful for my parents, loving sisters and their families, my husband and two daughters for their support and patience as I pursued these studies. I also would like to thank the members of my committee for their continuous guidance and support. I will be forever grateful. I would like to thank my major professor, Dr. Nasar U. Ahmed for his unlimited patience and guidance in the research process. Thank you to Dr. Ruby Natale for her teaching and mentorship as content expert in this research journey. Thank you to Dr. Maziak, Dr. Pekovic, and Dr. Veledar for their continued feedback, teaching, guidance, and support throughout the conduct of this dissertation study. I would not have been successful without their guidance in this journey. More importantly, I would like to thank God for the strength to pursue this academic endeavor and see it through. 


\section{ABSTRACT OF THE DISSERTATION \\ PREVALENCE AND DETERMINANTS OF OVERWEIGHT AND OBESITY IN \\ PRESCHOOLERS IN MIAMI-DADE COUNTY}

by

\section{Catherina Chang Martinez}

Florida International University, 2017

Miami, Florida

Professor Nasar U. Ahmed, Major Professor

The prevalence of childhood obesity continues to be a national public health problem in the United States. The child care and household environments affect the nutrition, physical activity, and screen-time behaviors in preschoolers. There were changes in nutrition, physical activity, and screen time regulations in child care centers in MiamiDade County in recent years to support the prevention of childhood obesity. This dissertation aimed to: (1) estimate the prevalence of overweight and obesity in 3-5-yearold children in Miami-Dade County; (2) identify the early infancy, dietary, and screentime risk factors associated with preschool overweight and obesity; and (3) assess child care centers' level of adherence to nutrition, physical activity, and screen-time regulations by center socioeconomic location. Child care center location was used as measure of child socioeconomic position (SEP).

A total of 366 3-5-year-old children from 34 centers in Miami-Dade County participated in the study. Overall, $29.8 \%$ of the children were overweight and $10.4 \%$ were 
obese. Middle-SEP children (35.3\%) and Hispanics (34.6\%) had the highest prevalence of overweight/obesity (O/O). Being Hispanic was associated with a nearly three-fold risk of being overweight/ obese (AOR: 2.91, 95\% CI 1.36, 6.21). Lack of daily consumption of fruits increased the risk of overweight in Hispanic children. Middle-SEP children reported lowest consumption of fruits and vegetables. There were significant differences in breastfeeding practices by ethnicity and SEP.

In the context of centers' adherence to local regulations, almost $80 \%$ of the centers adhered to serving low/fat-free milk to children older than 2-years-old. Only 34.5\% served vegetables and $75.9 \%$ served whole fruits during meals/snacks. Ninety-four percent of the centers had quiet and active play incorporated into their daily routines. All centers adhered to the two-hour screen-time limit for children older than 2-years-old. Low and middle-SEP centers fared better in the serving of fruits, vegetables, and low fat/ fat free milk when compared to high-SEP centers.

In conclusion, the high prevalence of overweight and obesity remains a public health problem. Our findings highlight child care centers as important venues for outreach to caregivers in the prevention of childhood overweight, especially for Hispanic and middleSEP groups living in Miami-Dade County. 


\section{TABLE OF CONTENTS}

CHAPTER PAGE

INTRODUCTION ..................................................................................

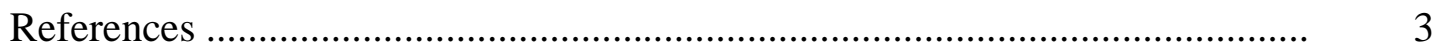

AIMS

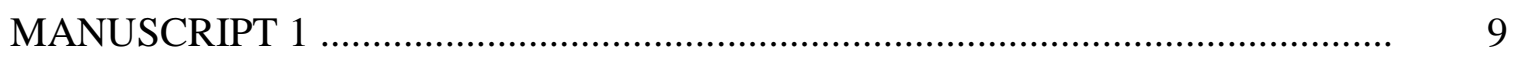

Abstract ................................................................................................ 9

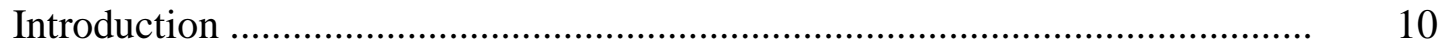

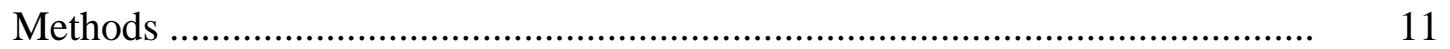

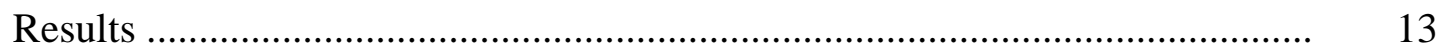

Discussion ...................................................................................... 27

Conclusions .................................................................................. 29

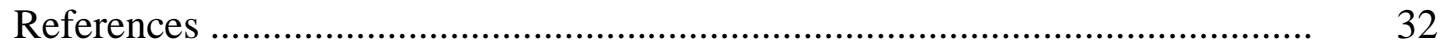

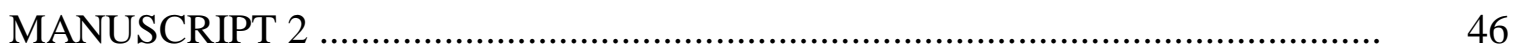

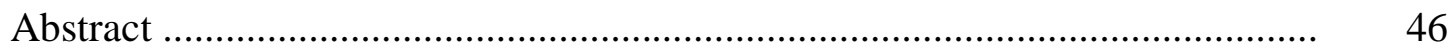

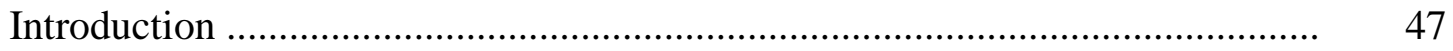

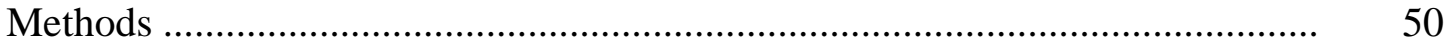

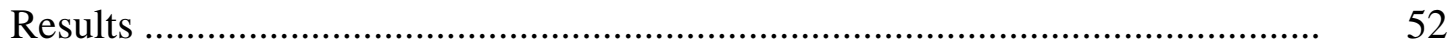

Discussion ........................................................................................

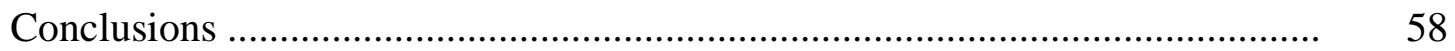

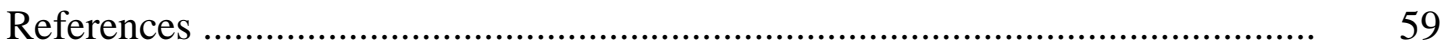

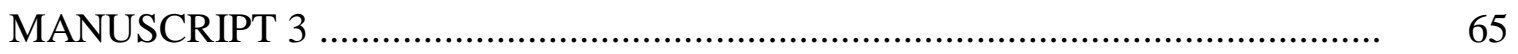

Abstract .............................................................................................. 65

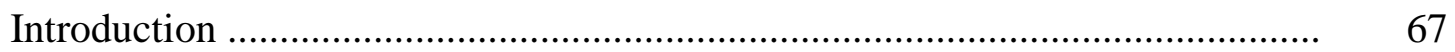

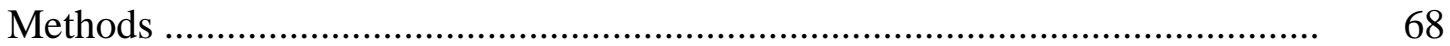

Results ......................................................................................

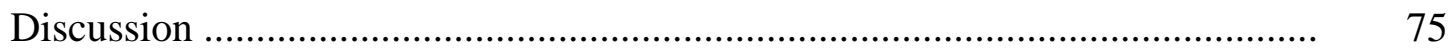

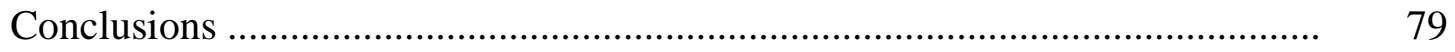

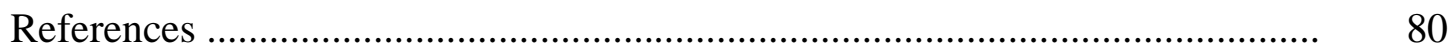

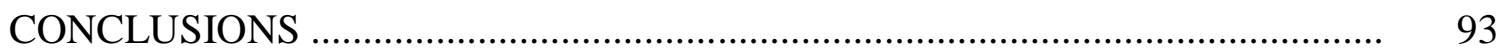

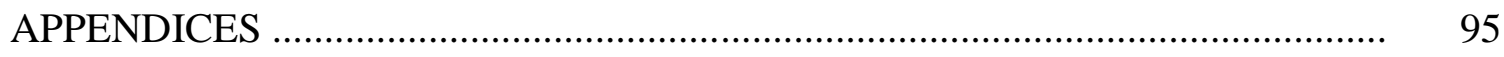

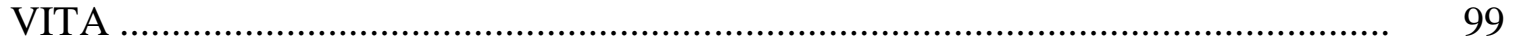




\section{ABBREVIATIONS AND ACRONYMS}

CCC Child Care Center

EPAO Environmental Physical Activity Observation Instrument

NHW Non-Hispanic White

NHB Non-Hispanic Black

O/O Overweight/obesity

SEP Socioeconomic Position 


\section{INTRODUCTION}

The prevalence of childhood obesity in the United States remains a national public health problem. Approximately 12.7 million 2-to-19-year-olds are reported to be obese (Ogden et al., 2014). Childhood overweight in preschoolers is likely to track into adult obesity (Nader et al., 2006) and increases the risk of metabolic syndrome, cardiovascular disease, and Type 2 diabetes (Messiah, et al., 2012; Pulgaron \& Delamater, 2014). Black and Hispanic minorities and lower socioeconomic groups are disproportionately affected by the increasing obesity rates. The knowledge of mechanisms underlying these differences remains limited (Wang \& Beydoun, 2007; Taveras, Gillman, Kleinman, et al, 2013).

Based on the ecological model, environmental factors in the household, school, community, and societal systems may influence on the dietary, physical activity, and sedentary behaviors associated with childhood obesity (Davison \& Birch, 2001). While the use of this model has been in use for researching factors associated with childhood obesity, childhood obesity studies have failed to account for neighborhood socioeconomic position and racial/ ethnic factors despite reports of an attenuation in the obesity disparities for some ethnic groups at the individual and community levels (Rossen, 2014). Therefore, the first aim of this research was to present a comprehensive conceptual model of determinants of obesity in preschoolers in the context of place, neighborhood physical, social environments, and residential segregation based on review of the literature.

The child care environment plays an important role in childhood obesity prevention. Approximately $60 \%$ of preschool-aged children spend twenty-four hours or more and 
consume 3-to-4 meals a day in child care in the United States (Freedman \& Alvarez, 2010). While the implementation of child care policies may contribute to better nutritional and physical activity practices for young children in these settings, previous studies indicate some states are lacking nutrition and physical activity policies that are consistent with national recommendations (Buscemi, Kanwischer, Becker, Ward, \& Fitzgibbon, 2015; Duffey, Slining, \& Benjamin Neelon, 2014). In Miami-Dade County, a Hispanic minority-majority metropolitan county, child care centers were required to adopt the provision of low/ fat-free milk, whole fruits and vegetables five days a week during meals and snack times. They were also required to adhere to two-hour screen time limits for children 2 years and older (CDC, 2013).

Since the introduction of these policies, to our knowledge, there are no published studies that assessed the current state of child care centers' practices and their adherence to these legislative rules. School-level economic disadvantage has been associated with higher obesity rates in school-aged children (Springer et al., 2015). However, its role has not been explored in the preschool population. The child care center location may then serve as a socioeconomic indicator of household socioeconomic position (SEP), especially when parents report child care proximity to home, cost, quality of the center, and the parents' cultural preference as reasons for selection of their child's child care center (Lindsay, Salkeld, Greaney, \& Sands, 2015). The aims of this study were to examine: (1) the current state of child care centers' adherence to nutrition, physical activity, and screen time legislative regulations; and (2) the differences in centers’ adherence to nutrition, physical activity, and screen time regulations by center SEP (low, middle, high) in Miami-Dade County. 
The household environment is also likely to contribute to the modeling of dietary and sedentary lifestyle behaviors in young children (Davison \& Birch, 2001). The knowledge of early life factors (breastfeeding, bottle-feeding, timing of complementary foods) in children in child care remains limited as these have been studied in isolation from other known determinants (Birch \& Doub, 2014; Grote \& Theurich, 2014; Sexton \& Natale, 2009). No published study, to our knowledge, has analyzed racial, ethnic, and socioeconomic differences in determinants of overweight/obesity in preschoolers using child care center location as an indicator of socioeconomic position (SEP). Guided by the maternal-child life course approach (Perez-Escamilla \& Kac, 2013) and socioecological framework (Davison \& Birch, 2001), the aims of our study were to examine the association between overweight/obesity and: (1) early feeding, dietary, and screen-time behaviors in preschoolers; and (2) race/ethnicity and socioeconomic position in 3-5-yearold children enrolled in child care centers located in various municipalities in MiamiDade County.

\section{References}

Bronfenbrenner, U. (1986). Ecology of the family as a context for human development: Research perspectives. Developmental Psychology, 22, 723 -742.

Birch LL, Doub AE. (2014). Learning to eat: birth to age 2 y. American Journal Clinical Nutrition.Mar;99(3):723S8S.

Centers for Disease Control and Prevention. (2013). Addressing Obesity Disparities. Social ecological model. Retrieved from http://www.cdc.gov/obesity/ health_equity/addressingtheissue.html 
Centers for Disease Control and Prevention. (2013). Communities putting prevention to work. Community profile: Miami-Dade County, Florida. Retrieved from http://www.cdc.gov/nccdphp/dch/programs/CommunitiesPuttingPrevention toWork/communities/profiles/obesity-fl_miami-dade-county.htm

Christoffel, K. K., Wang, X., \& Binns, H. J. (2012). Early origins of child obesity: Bridging disciplines and phases of development -- September 30--October 1, 2010. International Journal of Environmental Research and Public Health, 9(4), 12271262. doi:10.3390/ijerph9041227 [doi]

Dalenius, K., Borland, E., Smith, B., Polhamus, B., \& Grummer-Strawn, L. (2012). PediatricNutrition Surveillance 2010 Report. Atlanta: U.S. Department of Health and Human Services, Centers for Disease Control and Prevention; 2012. Retrieved from http://www.cdc.gov/pednss/ on February 15, 2014.

Davison, K. K., \& Birch, L. L. (2001). Childhood overweight: a contextual model and recommendations for future research. Obesity Reviews, 2(3), 159-171.

Elder, Arredondo, et al., 2009; Elder, J.P., Arredondo, EM., Campbell, N., Baquero, B., Duerksen, S., Ayala, G., et al. (2010). Individual, family, and community environmental correlates of obesity in Latino elementary school children. Journal of School Health, 80(1): 20-30, doi: 10.1111/j.1746-1561.2009.00462.x. Erratum in: J Sch Health. 2010 Mar;80(3):159. Crespo, Noc C [corrected to Crespo, Noe C] [doi].

Freedman, M. R., \& Alvarez, K. P. (2010). Early childhood feeding: Assessing knowledge, attitude, and practices of multi-ethnic child-care providers. Journal of the American Dietetic Association, 110(3), 447-451. doi:10.1016/j.jada.2009.11.018; 10.1016/j.jada.2009.11.018

Florida Department of Health in Miami-Dade County (2013). 2013 Miami-Dade Community Health Needs Assessment Household Survey Report. Omaha, Nebraska: Professional Research Consultants, Inc.

Flores, G., \& Lin, H. (2013). Factors predicting severe childhood obesity in kindergarteners. International Journal of Obesity, 7: 31-39.

Forrest, C.B., \& Riley, A.W. (2004). Childhood origins of adult health: a basis for lifecourse health policy. Health Affairs, 23(5): 155-64.

Fox, M., Glantz, F., Endahl, J., \& Wilde, J. (1997). Early Childhood and child care study (Vol 25). Alexandria, VA: U.S. Department of Agriculture. 
Grote, V., \& Theurich, M. (2014). Complementary feeding and obesity risk. Current Opinion in Clinical Nutrition and Metabolic Care, 17(3), 273-277. doi:10.1097/MCO.0000000000000054 [doi]

Harrison, K., Bost, K. K., McBride, B. A., Donovan, S. M., Grigsby-Toussaint, D. S., Kim, J., Liechty, J. M., Wiley, A., Teran-Garcia, M., \& Jacobsohn, G. C. (2011). Toward a developmental conceptualization of contributors to weight imbalance in childhood: The Six-Cs model. Child Development Perspectives, 5 (1), 50-58.

Kuczmarski, R., Ogden, C., Guo, S., \& al., e. (2002). CDC growth charts for the United States: Methods and development.: Vital Health Stat.

McConahy, K. L., Smiciklas-Wright, H., Mitchell, D. C., \& Picciano, M. F. (2004). Portion size of common foods predicts energy intake among preschool-aged children. Journal of the American Dietetic Association, 104(6), 975-979. doi:10.1016/j.jada.2004.03.027 [doi]

Messiah, S.E., Arheart, K.L., Natale, R.A., Hlaing, W.M., Lipshultz, S.E., \& Miller, T.L. (2012). BMI, waist circumference, and selected cardiovascular disease risk factors among preschool-aged children. Obesity, 20(9): 1942-9. doi: 10.1038/oby.2011.353. Epub 2011 Dec 8.

Messiah, S. E., Asfour, L., Arheart, K. L., Selem, S. M., Uhlhorn, S. B., \& Natale, R. (2014). Relationship Between Parent Demographic Characteristics, Perinatal and Early Childhood Behaviors, and Body Mass Index Among Preschool-Age Children. Journal Immigrant Minority Health. doi: 10.1007/s10903-014-0079-7

Miami Dade Health Department. (2011). Consortium for a Healthy Miami-Dade. Initiatives. Communities putting prevention to work. Retrieved from http://www.healthymiamidade.org/ committees/ children-issues/initiatives on March 2, 2015.

Nader, P. R., O'Brien, M., Houts, R., Bradley, R., Belsky, J., Crosnoe, R.,, et al. (2006). Identifying risk for obesity in early childhood. Pediatrics, 118(3), e594-601. doi:118/3/e594 [pii]

Natale, R. A., Lopez-Mitnik, G., Uhlhorn, S. B., Asfour, L., \& Messiah, S. E. (2014). Effect of a child care center-based obesity prevention program on body mass index and nutrition practices among preschool-aged children. Health Promotion Practice, 15(5), 695-705. doi:10.1177/1524839914523429 [doi]

Natale, R., Scott, S. H., Messiah, S. E., Schrack, M. M., Uhlhorn, S. B., \& Delamater, A. (2013). Design and methods for evaluating an early childhood obesity prevention program in the childcare center setting. BMC Public Health, 13, 78-2458-13-78. doi:10.1186/1471-2458-13-78 [doi] 
Ogden, Carroll, Kitt, \& Flegal, 2014; Ogden, C. L., Carroll, M. D., Kit, B. K., \& Flegal, K. M. (2014). Prevalence of childhood and adult obesity in the United States, 2011-2012. JAMA : The Journal of the American Medical Association, 311(8), 806-814. doi:10.1001/jama.2014.732 [doi]

Perez-Escamilla, R., \& Kac, G. (2013). Childhood obesity prevention: a life-course framework. International Journal Obesity Supplement, 3(Suppl 1), S3-s5. doi:10.1038/ijosup.2013.2

Pulgaron, E. R., \& Delamater, A. M. (2014). Obesity and type 2 diabetes in children: Epidemiology and treatment. Current Diabetes Reports, 14(8), 508-014-0508-y. doi:10.1007/s11892-014-0508-y [doi]

Sexton, S., \& Natale, R. (2009). Risks and benefits of pacifiers. American Family Physician, 79(8), 681- 685.

Taveras, E. M., Gillman, M. W., Kleinman, K. P., Rich-Edwards, J. W., \& Rifas-Shiman, S. L. (2010). Racial/ ethnic differences in early life risk factors for childhood obesity. Pediatrics, 125(4): 686-95. doi: 10.1542/peds.2009-2100. Epub 2010 Mar 1.

Taveras, E. M., Gillman, M. W., Kleinman, K. P., Rich-Edwards, J. W., \& Rifas-Shiman, S. L. (2013). Reducing racial/ ethnic disparities in childhood obesity: the role of early life factors. JAMA Pediatrics, 167(8):731-8. doi: 10.1001/jamapediatrics.2013.85.

U.S. Department of Agriculture. (2014). Choose MyPlate Program. Retrieved from http://www.choose myplate.gov/about.html on December 12, 2014.

U.S. Census Bureau (2014). State and County Quick Facts. Florida. Miami-Dade County. Retrieved from http://quickfacts.census.gov/qfd/states/12000.html

Wang, Y., \& Beydoun, M. A. (2007). The obesity epidemic in the United States--gender, age, socioeconomic, racial/ethnic, and geographic characteristics: A systematic review and meta-regression analysis. Epidemiologic Reviews, 29, 6-28. doi:mxm007 [pii]

Ward DS, Hales D, Haverly K, et al. (2008). An instrument to assess the obesogenic environment of child care centers. American Journal Health Behavior, 32:380-6.

Williams, H. G., Pfeiffer, K. A., O'Neill, J. R., Dowda, M., McIver, K. L., Brown, W. H., \& Pate, R. R. (2008). Motor skill performance and physical activity in preschool children. Obesity (Silver Spring, Md.), 16(6), 1421-1426. doi:10.1038/oby.2008.214 [doi] 


\begin{abstract}
AIMS
The aims of this dissertation were to:

Manuscript 1: Residential Segregation, Neighborhood Social and Physical Context in Obesity Disparities in Hispanic Preschoolers: A Conceptual Model

Aim:

To present a comprehensive conceptual model of determinants of obesity in preschoolers in the context of place, neighborhood physical, social environments, and residential segregation.
\end{abstract}

Manuscript 2: State Mandated Nutrition, Physical Activity, and Screen-time Policies in Child Care Centers

Aims:

(1) To examine the current state of child care centers' adherence to nutrition, physical activity, and screen time legislative regulations.

(2) To examine the differences in child care centers' adherence to nutrition, physical activity, and screen time regulations by center socioeconomic position (low, middle, high) in Miami-Dade County.

(3) To observe the differences in total active play, outdoor play, and screen time by centers' socioeconomic position. 
Manuscript 3: Exploring Early life, Dietary, Sedentary, Racial/Ethnic and Socioeconomic Determinants of Overweight and Obesity in Preschoolers

Aims:

(1) To examine the association between overweight/obesity and early feeding, current dietary, and screen-time behaviors in preschoolers.

(2) to examine the association between these determinants, race/ethnicity, and socioeconomic position in preschoolers from child care centers located in various municipalities in Miami-Dade County. 


\title{
MANUSCRIPT 1
}

\section{Residential Segregation, Neighborhood Social and Physical Context in Obesity Disparities in Hispanic Preschoolers: A Conceptual Model}

\begin{abstract}
BACKGROUND: During the last decade, there has been a significant inclusion in obesity prevention studies from individual characteristics to household factors then neighborhood factors. The study of place in the context of early childhood obesity studies has been limited to the food and physical built environment. AIM: To develop a new model conceptual framework examining the role of place and residential segregation in the context of race, ethnicity, social position, and socioeconomic disparities. RESULTS: The neighborhood social and physical factors as well as organizational, household and/or individual factors may serve as mediators of the correlation between residential segregation and obesity in Hispanic preschoolers. Segregated residential areas may represent supportive environments for new immigrants through the social networks, common languages, practices, and norms. CONCLUSIONS: We presented this model as a strategy to guide in the specification of factors in testable analytical models of racial residential segregation and obesity in Hispanic preschool children early in the life course. The model also has implications for other ethnic and migrant minorities living in ethnic enclaves in the United States. Recommendations for future research need are identified. KEYWORDS: residential, segregation, social position, preschooler, obesity, neighborhood, Hispanic
\end{abstract}




\section{Introduction}

Childhood obesity is a substantial national public health problem in the United States. Approximately 12.7 million children have been affected by the increasing obesity rates in the past decade (Ogden, Carroll, Kit, \& Flegal, 2014). Compared with Whites, Hispanic and non-Hispanic Black children and adolescents reported higher obesity rates in 2011-2012 (22.4\% and 20.2\% respectively) (Ogden et al., 2014). Obesity in children carries several negative consequences, including the development of cardiovascular disease, Type 2 Diabetes Mellitus, low self-esteem, depression, and stigma (Freedman, Mei, Srinivasan, Berenson, \& Dietz, 2007; Han, Lawlor, \& Kimm, 2010; Messiah et al., 2012; Puhl \& Latner, 2007; Pulgaron, 2013). Because differences in individual-level risk factors cannot fully explain the racial and ethnic disparities related to weight outcomes in children, social contextual influences at the neighborhood and community levels have been the focus of recent studies (Debbink \& Bader, 2011; Suglia et al., 2016).

Racial residential segregation or the geographical clustering of racial and ethnic groups has been a determinant of racial inequalities in the United States (AcevedoGarcia, Osypuk, McArdle, \& Williams, 2008; Massey \& Denton, 1989; Williams \& Collins, 2001). Living in the midst of economically disadvantaged urban communities exposed to high levels of crime (Jones-Webb \& Wall, 2008; Krivo, Peterson, \& Kuhl, 2009) and higher obesity rates have been reported for Black and Hispanic minorities living in highly segregated residential areas (Corral, Landrine, \& Zhao, 2014; Kershaw, Albrecht, \& Carnethon, 2013). The healthy migrant or Hispanic/ Latino migrant paradox has not been reflected in Hispanic preschool overweight children (Baker, Rendall, \& Weden, 2015; Kim, Collins, \& Grineski, 2014). First and second generation migrant 
Hispanic preschoolers living in Hispanic migrant enclaves and Hispanic minoritymajority metropolitan areas are experiencing increasing obesity rates (Messiah et al., 2015; Nobari et al., 2013).

While the socioecological model has been currently in use for researching factors associated with childhood obesity, there are limitations associated with the use of this model (Davison \& Birch, 2001; Dev, McBride, Fiese, Jones, \& Cho, 2013). The childhood obesity community studies have failed to account for neighborhood socioeconomic position and racial/ ethnic factors despite reports of an attenuation in the obesity disparities for some ethnic groups at the individual and community levels (Rossen, 2014). It has been difficult to establish causality of neighborhood effects versus selective residential mobility due to the cross-sectional nature of the studies (Jokela, 2014). Current models have been limited in examining temporality in the order of factors for person-place interaction across the lifespan (Daniel, Moore, \& Kestens, 2008). Therefore, our understanding of the timing of exposure to these multiple factors continues to be limited. Understanding the temporal and cumulative effects of these factors is of great importance, especially when studies report critical periods in the life course (pre-pregnancy, prenatal, infancy, early childhood) increasing the risk of obesity throughout the lifespan (Pudrovska, Logan, \& Richman, 2014). A maternal-child life course framework has further been advocated in the studies (Perez-Escamilla \& Kac, 2013).

\section{Methods}

In the midst of the increasingly persistent disparities in childhood obesity, there is a need to reexamine existing models and develop new model conceptual frameworks with 
particular attention to segregation contextual factors in the neighborhood social and physical environments. Therefore, the objective of this paper is to present a comprehensive conceptual model of determinants of obesity in preschoolers in the context of place, neighborhood physical, social environments, and residential segregation. In segregated environments with increased prevalence of obesity, we hypothesize that ethnic-related factors in the neighborhood social and physical environment are likely to mediate the association between residential segregation and obesity in Hispanic preschool children. The proposed model, Segregation, Social Position, Intermediate, Proximate, and Immediate (SSIPI) Health Risk Model, is an adaptation of the Healthy Environments Partnership conceptual model (HEP) (Schulz et al., 2005) and a conceptual framework of biosocial pathways in the relationship between geospatial clustering of disadvantage and cardiovascular and glycemic disease (Daniel, Moore, \& Kestens, 2008).

There are distinctive benefits to the application of this model as it exclusively recognizes the role of socioeconomic position, race-based residential segregation, and income inequalities as fundamental factors likely to influence on the neighborhood social and physical environments, intermediate, proximate, and immediate sociodemographic and behavioral factors associated with childhood obesity, and ultimately cardiovascular risk (Schulz et al., 2005). We elaborate on the role of federal, state, and local policies and programs in moderating racial/ ethnic residential segregation while accounting for the effects of time during the person-place interactions throughout the life course. While the focus of this model is on preschool Hispanic children, the use of this model has relevance to other racial/ethnic groups affected by the increased prevalence of obesity and living in 
segregated environments. In the model we attempt to explain biological plausibility and temporarily through biosocial pathways linking place to health throughout the various stages in the life course (Daniel, et al., 2008). Lower socioeconomic position resulting from lack of social, geographical mobility and income inequalities is likely to present cumulative risks of overweight and obesity (Elhakeem, Hardy, Bann, Caleyachetty, Cosco, et al., 2016; Ravensbergen, Buliung, Wilson, and Faulkner, 2016). In this review we discuss the factors associated with overweight and obesity as well as methodological considerations for future research work in Hispanic preschoolers living in segregated environments.

\section{Results}

$\underline{\text { Segregation, Social position, Intermediate, Proximate, and Immediate (SSIPI) Health }}$

\section{$\underline{\text { Risk Model }}$}

$\underline{\text { Racial/ ethnic residential segregation and socioeconomic inequalities }}$

Racial/ethnic residential segregation is presented in figure 1 as a fundamental factor that influences intermediate, proximate, and immediate risk factors of obesity in children in general, however, our focus here on Hispanic preschool children. Racial/ ethnic residential segregation, a form of institutional discrimination, arises from individual residential preferences and discriminatory and exclusionary practices and policies in housing markets (Massey \& Denton, 1989). Foreign-born Hispanics are more segregated from non-Hispanic Whites than their U.S. born counterparts (Iceland \& Scopilliti, 2008) with differential patterns based on regional concentration, population size, nativity, English language ability, and local socioeconomic conditions (Massey \& Denton, 1989). 


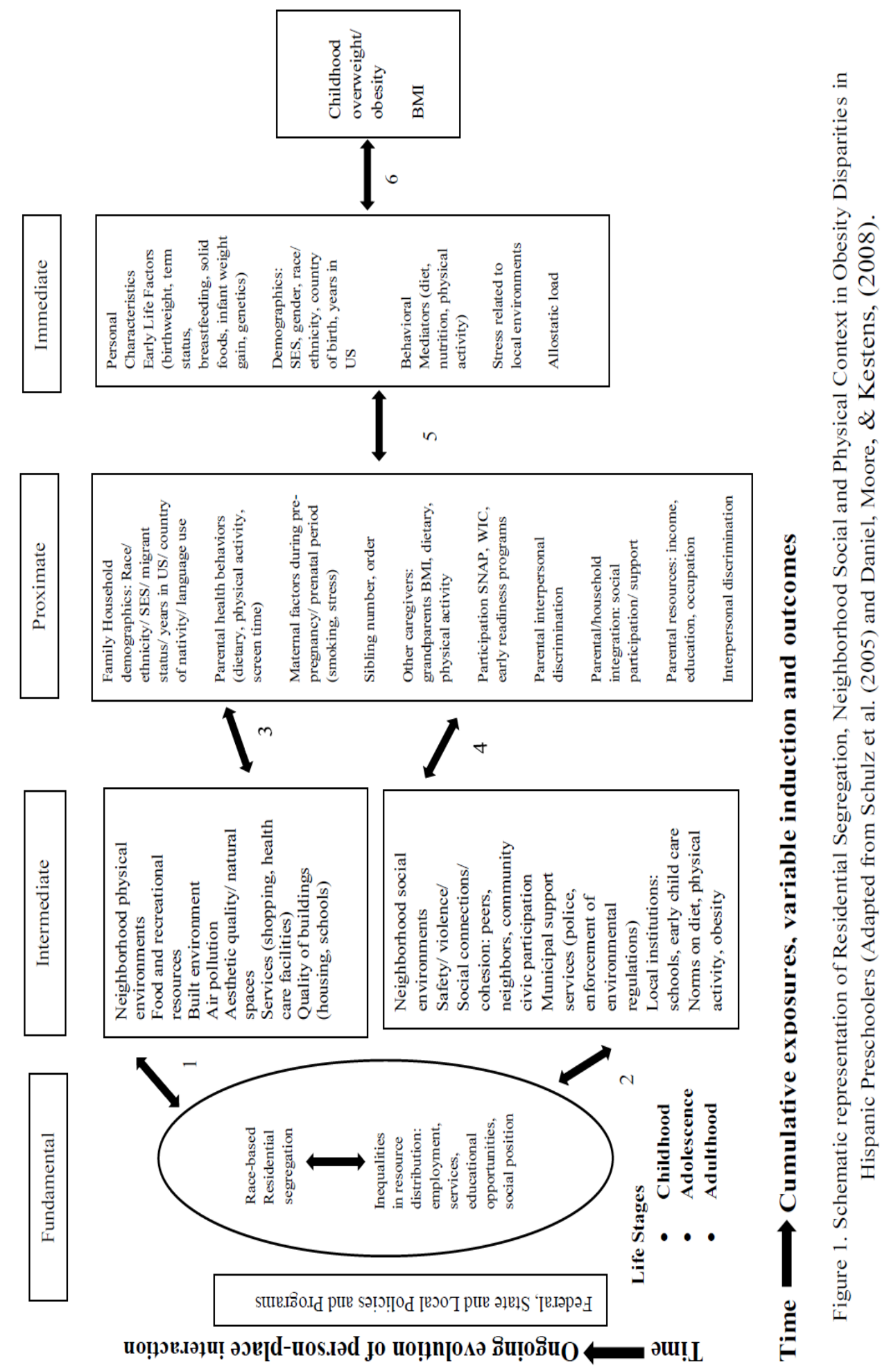


Segregated residential areas represent areas of high poverty and decreased access to resources, especially for those limited by blocked social and spatial mobility (Borjas, 1998; Osypuk, Bates, \& Acevedo-Garcia, 2010). Residential segregation has been correlated with inequalities in the quality of education, employment opportunities, income levels, access to retail outlets and health care providers, and poor neighborhood quality (Stromgren et al., 2014; Williams \& Collins, 2001). In the model, this process is presented with the use of bi-directional arrows to indicate the reciprocal effect between residential segregation and inequalities to resources (Schulz et al., 2005).

Hispanic immigrants working in ethnic enclaves report negative economic outcomes as a result of undesirable jobs and lower wages when compared to those working in mainstream economies (Xie \& Gough, 2011). Despite these findings, some studies report living in Hispanic enclaves being associated with increased access to social networks, social support, and healthy practices and norms for Hispanic migrants (Kim et al., 2014; Osypuk et al., 2010). Hispanic and foreign-born neighborhoods have been reported as having a protective effect against obesity in children (Kimbro \& Denney, 2013). However, these findings have not been consistent, especially when Hispanic preschoolers experience higher obesity rates compared to other ethnic groups in some geographical areas (Weedn, Hale, Thompson, \& Darden, 2014). The interaction effects of neighborhood deprivation and individual-level socioeconomic status appear to be more marked in Hispanic preschoolers when compared to non-Hispanic Whites and Blacks (Rossen, 2014). The studies further suggest increasing obesity risks for Hispanic preschoolers living in Spanish-speaking segregated areas, with individual factors, such as Spanish speaking as the household language mediating the association (Nobari et al., 
2013). These conflicting findings warrant the need to explore further the role of family household and individual factors in the context of segregated residential environments among Hispanics. We discuss these as intermediate, proximate, and immediate factors in the association with childhood obesity.

As proposed by Daniel et al. (2008), variation in the timing and intensity of the exposures resulting in variable induction times between exposure and disease outcome as individuals move from place to place and neighborhoods evolve over time (Daniel et al., 2008; Houghton, Kelleher, \& Duncan, 2003). Daniel et al (2008) describe the changes in structure and context as dynamic, evolving through time, reflected on the y axis. Communities may experience the effects of changes in policies and programs to prevent childhood obesity at the neighborhood level (Ritchie et al., 2015; Yoong et al., 2016). Reports from longitudinal studies indicate changes in child body mass index (BMI) may take place in response to changes in the neighborhood food store environment across time (Chen \& Wang, 2016). With changes in environmental characteristics, mobility may serve a protective role in weight gain during the lifespan (Jones, 2015). The time factor on the $\mathrm{x}$ axis signifies the cumulative exposures, whether immediate, proximate, intermediate, or fundamental, prone to variable induction and outcome times (Daniel et al., 2008; Schulz et al., 2005).

While the focus of this model is towards the framing of racial residential segregation, neighborhood social and physical contextual effects on preschoolers, the effects are likely to carry throughout the lifespan. Childhood, adolescence, and adulthood are presented as part of the life stages on the $\mathrm{x}$ axis as they represent distinctive, vulnerable periods in the tracking of overweight and obesity throughout the life course 
(Davidson et al., 2014; Johnson et al., 2014). During childhood, school-related factors, including peers, the school environment, and the neighborhood surrounding the school environment are likely to impact on children's risk of obesity (Elder, et al., 2010). Adolescents and youth are subject to different types of influences, including peers, the media over the type of foods and activities in the school or social network. Ultimately, the increased in BMI is likely to track in the adult years, impacting on cardiovascular disease risk as well as other obesity-related chronic diseases.

Intermediate Factors: Neighborhood Physical and Social Environments

Racial/ethnic residential segregation and its associated inequalities are likely to affect the quality of the neighborhood physical and social environments where Hispanic children reside (arrows 1 and 2). Hispanic and Black children face increasing inequalities in accessibility to higher-opportunity neighborhoods when compared to non-Hispanic Whites (Acevedo-Garcia et al., 2008; Rossen, 2014). For Mexican-Americans living below poverty level, the risk of obesity does not attenuate even in the midst of lower neighborhood deprivation as observed in non-Hispanic Whites (Rossen, 2014). Hispanics living in neighborhoods with higher immigrant composition have reported worse neighborhood factors (walkability, social cohesion or trust, and lower neighborhood civic participation) when compared to neighborhoods with lower proportion of foreign-born Hispanics (Osypuk, Diez Roux, Hadley, \& Kandula, 2009). Factors such as parental perception of physical and social neighborhood disorder, traffic safety, availability of places for child's physical activity, and neighborhood social informal controls have been associated with lower levels of physical activity and higher Body Mass Index (BMI) in Hispanic preschoolers (Mendoza, McLeod, Chen, Nicklas, \& Baranowski, 2014; 
O'Connor et al., 2014). Mothers of foreign-born Hispanics living in neighborhoods with higher concentration of immigrants report lower levels of physical activity and higher levels of physical and social neighborhood disorder (Brewer \& Kimbro, 2014). Therefore, parents are more likely to have their children engage in sedentary behaviors, especially the increased use of screen time (Mendoza et al., 2014; O'Connor et al., 2014). This is represented by the bidirectional arrows between the interpersonal parental factors and the intermediate factors in the conceptual model (arrows 3 and 4). Municipal support systems, including adequacy and competence of police, fire-fighting, and other municipal services can help moderate the negative physical and social neighborhood factors as they relate to safety in residentially segregated environments (Schulz et al., 2005).

Lower socioeconomic status communities are also more likely to experience higher concentration of air pollutants (Hajat, Hsia, \& O'Neill, 2015). Higher prenatal exposure to air pollutants has been associated with higher body size in young children, after adjustment for gender, age, ethnicity, birth weight, maternal receipt of public assistance, and pre-pregnancy obesity (Rundle et al., 2012). Exposure to pollutants is also likely to increase the risk of low birth weight and small-for-gestational-age births (Vinikoor-Imler, Davis, Meyer, Messer, \& Luben, 2014). These findings have been reported in infants born to women with lower socioeconomic status, chronic hypertension, diabetes and high BMI (Laurent et al., 2014). Next, the food environment represents another important factor to examine in segregated residential areas for its implications in the prevention of childhood obesity. Non-chain supermarkets, grocery stores, fast-food restaurants, and energy-dense foods are more prevalent in low-income, minority neighborhoods (Zenk et al., 2005). Hispanic census tracts with up to $20 \%$ of 
households living below the federal poverty level report having the most grocery stores (Bower, Thorpe, Rohde, \& Gaskin, 2014; Zenk et al., 2005). These factors are likely to contribute to the accessibility of fresh fruit, vegetables, low-fat milk, and high-fiber foods (Jaskiewicz et al., 2013; Larson, Story, \& Nelson, 2009).

Some studies report children's increasing weight status despite proximity to local supermarkets with accessibility to healthier food options (Chaparro et al., 2014; OhriVachaspati, Lloyd, Delia, Tulloch, \& Yedidia, 2013)._While there are no studies on residential segregation and food options for preschoolers, limited studies report Black adults' selection of food markets being associated with lower BMI status while supermarkets, wholesale clubs, and food pantries have resulted in opposite findings (Hosler, Michaels, \& Buckenmeyer, 2016). Small corner groceries are more prevalent in Black neighborhoods as compared to racially mixed and white neighborhoods in predominantly Black-White communities (Morland, Wing, Diez Roux, \& Poole, 2002; Zenk, Mentz, Schulz, Johnson-Lawrence, \& Gaines, 2016). Hispanics living in neighborhoods with higher immigrant composition are more likely to being exposed to healthier food environments (Osypuk et al., 2009). Findings from limited studies suggest that there are differentials in quality of the diets in Hispanics by ethnic subgroups. One study reported differentials in the children's consumption of ethnic foods, with Mexicans having the healthier diets and lower obesity rates when compared to Dominicans and Puerto Rican subgroups (Vangeepuram, Mervish, Galvez, Brenner, \& Wolff, 2012).

Organizational factors in the social environment, such as the child care center or early learning environment present opportunities in the prevention of childhood obesity (Benjamin Neelon, Taveras, Ostbye, \& Gillman, 2014). Lower-income Hispanic children 
attend preschool classrooms segregated by family income, race, and ethnicity (Reid \& Kagan, 2015). In some metropolitan areas there is preference by Hispanic families to have their children attend family child care centers operated by Hispanic staff (Lindsay, Salkeld, Greaney, \& Sands, 2015). In these settings, educators play a significant role in the promotion and modeling of healthy behaviors in young children (Ward, Belanger, Donovan, \& Carrier, 2015). Their perceptions and beliefs are important as they may shape the physical activity, screen-time, and dietary behaviors in children under their care (Tovar, Mena, Risica, Gorham, \& Gans, 2015). Policy-related factors displayed to the left of the conceptual model have significant implications as federal, state, local policies and programs may help moderate the effects of residential segregation and inequalities for Hispanic minorities. Changes in child care regulations in nutrition, physical activity, and screen-time have been associated with lowering prevalence of obesity in low-income preschool groups (Sekhobo et al., 2014). Other factors such as the centers' participation in the Child and Adult Care Food program (CACFP) moderately increases the consumption of milk, fruits, vegetables, and meat/meat alternatives, and may reduce the prevalence of overweight and underweight in young children (Korenman, Abner, Kaestner, \& Gordon, 2013; Ritchie et al., 2012).

\section{Proximate Factors: Parental Household Factors}

Parental household factors in the context of residential segregation in the preschool Hispanic population need to be explored. Based on studies in older children, foreign-born Hispanic immigrants are more likely to have lower family income and maternal education, and to live in areas of higher immigrant density and greater linguistic isolation (Gordon-Larsen, Harris, Ward, \& Popkin, 2003). Rapid acculturation of 
overweight-related behaviors is likely to take place in U.S. born relative to foreign-born immigrants. However, children and adolescents tend to participate in global culture more quickly than their parents (Gordon-Larsen et al., 2003; Sobal, 2001). Longer U.S. residence has been associated with increased overweight later in the life course, as observed in Puerto Rican and Cuban youth (Gordon-Larsen et al., 2003). Acculturation factors such as language use in the household also need to be explored, especially when children of Spanish-speaking-only households are twice as likely to have an obese preschool child when compared to English-only speaking households (Messiah et al., 2015).

It has been well established that parents play an important role in the prevention of obesity in children during the preschool age. Children's dietary and physical activity behaviors have been associated with parental dietary and physical activity behaviors (Pearson, Biddle, \& Gorely, 2009; Ruiz, Gesell, Buchowski, Lambert, \& Barkin, 2011). The parental influences are likely to moderate the child's individual factors, thus increasing his/her risk of obesity (arrow 5). Other factors such as parents' food practices and their perception of a healthy weight may also play a role in their child's weight status (Chaparro, Langellier, Kim, \& Whaley, 2011; Sherry et al., 2004). Parental underestimation of their child's weight status is more prevalent in Hispanic parents of an overweight/obese child when compared to other racial/ethnic groups (Boutelle, Fulkerson, Neumark-Sztainer, \& Story, 2004; Gauthier \& Gance-Cleveland, 2015, 2016). The family and cultural context are also important, as Hispanic mothers report pressures of familial and cultural influences endorsing a "chubby child" despite health-related and social consequences of childhood overweight (Lindsay, Sussner, Greaney, \& Peterson, 
2011). These factors need to be studied, especially when lower-income Spanish speaking families with young children are likely to have traditional foods more readily available than American foods (Evans et al., 2011).

Factors such as food availability and cost, health concepts, the eating habits of children, and long work hours also play a role in the parents' selection of foods brought into the home environment (Gray, Cossman, Dodson, \& Byrd, 2005). Lower-income Hispanic children are likely to experience food insecurity and this in turn increases their risk of obesity (Mangini, Hayward, Dong, \& Forman, 2015; Papas, Trabulsi, Dahl, \& Dominick, 2015). Higher food security has been associated with higher consumption of fruit and vegetables and lower consumption of unhealthy foods, moderated by ethnicity in Hispanic and Haitian households (Asfour et al., 2015). Low-income Hispanic households face higher rates of food insecurity than national average (26.2\%) when compared to Black and White, non-Hispanic households (Coleman-Jensen, Nord, Andrews, \& Carlson, 2011). The presence of federally funded nutrition assistance programs such as the Supplemental Nutrition Assistance Program (SNAP) may help moderate the food insecurity in the household for parents and preschool Hispanic children living in segregated residential areas (Mabli \& Worthington, 2014). Participation in these programs may also serve as a vehicle for nutrition education and promotion of physical activity in Hispanic vulnerable populations (Mabli \& Worthington, 2014; Stang \& Bayerl, 2010).

Maternal factors have received increased attention in the programming of childhood obesity early in the life course. Findings from longitudinal and cross-sectional studies report maternal adversity and chronic exposure to stress in the life course increase 
the risk of pre-pregnancy obesity, maternal gestational weight gain, and obesity risk in the offspring (Ranchod et al., 2016; Boney, Verma, Tucker, \& Vohr, 2005). An increase in maternal stressors has been reported to amplify a food secure child's probability of being overweight or obese (Gundersen, Lohman, Garasky, Stewart, \& Eisenmann, 2008). For Hispanic mothers, stress-related factors including interpersonal discrimination have also been associated with increased obesity risks in Hispanic preschoolers (AcevedoGarcia, Rosenfeld, Hardy, McArdle, \& Osypuk, 2013; Kelly, Becares, \& Nazroo, 2013). Low-birthweight (weight $<2500$ grams) presents increased obesity risks when combined with accelerated weight gain during the first six months of life (Bjerregaard et al., 2014; Sacco, de Castro, Euclydes, Souza, \& Rondo, 2013). Simultaneously, living in disadvantaged neighborhoods, comprised of poverty, deprivation, racial residential segregation or racial composition, and crime increases the risk for preterm birth and low birth weight in infants (Ncube, Enquobahrie, Albert, Herrick, \& Burke, 2016).

Differences have been observed between foreign and U.S. born Hispanic enclaves, with U.S. born Mexican American mothers living in U.S. born Hispanic enclaves reporting higher prevalence of low-birthweight rates when compared to those living in Mexicanborn enclaves (Osypuk et al., 2010).

Other maternal factors such as pregnancy-induced hypertension, preeclampsia, undernutrition, smoking during pregnancy, hypercholesterolemia, increased glucocorticoid secretion, and chronic exposure to stress have been reported in highprevalence low-birthweight segregated areas (Szostak-Wegierek \& Szamotulska, 2011). However, maternal smoking during pregnancy, an established risk factor for childhood obesity, is prevalent in Hispanic women living in less racially segregated area with higher 
exposure to non-Hispanic White groups (Yang, Shoff, Noah, Black, \& Sparks, 2014). Access to prenatal care may help moderate the segregation effects in Hispanic mothers, as they report inadequate prenatal care utilization associated with increased risk of prematurity and other negative birth outcomes (Partridge, Balayla, Holcroft, \&

Abenhaim, 2012). The limited studies indicate Hispanic and Black lower-income women are less likely to seek prenatal care when compared to non-Hispanic Whites (Chang, Tabet, Elder, Kiel, \& Flick, 2016; Chung, Gregorich, Armitage, Gonzalez-Vargas, \& Adams, 2014). Factors such as the concentration of community hospitals and hospital obstetric beds and supply of health care professionals are likely to help mitigate the negative effects of residential segregation in highly prevalent low-birthweight areas (Nyarko \& Wehby, 2012). The mode of delivery of prenatal education and medical care for ethnic minorities such as Hispanics may contribute to their increase in prenatal care utilization (Lindberg, DeBoth, \& Anderson, 2016; Tandon, Cluxton-Keller, Colon, Vega, \& Alonso, 2013).

$\underline{\text { Immediate Individual Factors }}$

Immediate factors such as the child's dietary and physical activity behaviors present a more direct effect in the development of childhood obesity (arrow 6). Living in immigrant enclaves may be differentially protective for Hispanic children based on individual and household factors (Glick \& Yabiku, 2015). While higher immigrant density may be significantly more protective for lower income children, it may be less protective for those in worse general health, including those with higher BMI measures (Kim et al., 2014). As displayed in the model, parental and household factors will influence on the immediate individual factors (arrow 6). Despite Hispanic households' 
access to a yard or open space and usable play equipment, Hispanic children, especially foreign-born Hispanic children report lower levels of physical activity (Brewer \& Kimbro, 2014) (Chuang, Sharma, Skala, \& Evans, 2013; Innella, Breitenstein, Hamilton, Reed, \& McNaughton, 2015). Studies report television watching during meals and using TV as babysitter and tool to learn English being prevalent in Hispanic children (Lindsay, Sussner, Greaney, \& Peterson, 2009). Recent studies report racial and ethnic differences in the proportion of children meeting the 5-2-1-0 targets ( $\geq 5$ servings of fruit and vegetables, $\leq 2$ hours of screen-time, $\geq 1$ hour of physical activity, and 0 sugar-sweetened beverages daily), and Hispanic children reporting the lowest levels of physical activity. Overall, they are second to Blacks in not meeting these overall targets (Haughton, Wang, \& Lemon, 2016).

The social and physical neighborhood context may contribute to the development of childhood obesity by an accumulation of disadvantage over time through exposures during critical periods in the developmental trajectories (Daniel et al., 2008; Galobardes, Smith, \& Lynch, 2006). Exposures to negative, stressful conditions as well as those that may place a physiological demand, may result in overexposure to neural, endocrine, and immune stress mediators (allostatic load), leading to increasing weight, elevated glucose levels, lower high density lipoproteins, and cardiovascular risk (Schulz et al., 2012). Factors such as nativity, migration history, including time since immigration, number of residential moves, duration of residency, and intensity of exposures between and within places need to be considered with differential individual experiences though the life course (Daniel et al., 2008). Some of these factors have been associated with increasing weight status in Hispanic ethnic minorities (Glick \& Yabiku, 2015; Goulao, Santos, \& 
Carmo, 2015). The life-course perspective is necessary to frame the mechanisms by which risk factors in the early childhood period may contribute to the development of chronic diseases such as obesity during the life trajectory (Acevedo-Garcia et al., 2013; Daniel et al., 2008). Early childhood overweight and obesity track into the adulthood stage (Nader et al., 2006), and disparities in maternal/caregiver factors contribute to the programming of obesity early in the life course (Dixon, Pena, \& Taveras, 2012).

Other factors such as early initiation and longer duration of breastfeeding present protective effects in the development of childhood obesity (Spatz, 2014). Hispanics report lower breastfeeding rates in eastern states (Lind, Perrine, Li, Scanlon, \& GrummerStrawn, 2014; Scanlon, Grummer-Strawn, Li, \& Chen, 2010). Breastfeeding rates in Hispanics are likely to decrease with greater U.S. acculturation (Perez-Escamilla \& Putnik, 2007; Rassin et al., 1994; Singh, Kogan, \& Dee, 2007) and second and thirdgeneration status (Barcelona de Mendoza, Harville, Theall, Buekens, \& Chasan-Taber, 2016). Spanish-speaking mothers are more likely to initiate, intend, and maintain breastfeeding when compared to English-speaking Hispanic mothers, non-Hispanic Whites, and Black mothers (McKinney et al., 2016). In the promotion of lactation, employment requirements to have a site and/or break time for mothers to lactate and the presence of a state coalition funded for a longer period of time have been associated with higher breastfeeding state rates (Dozier \& McKee, 2011). Supportive programs such as the Supplemental Nutrition Program for Women, Infants, and Children (WIC) present opportunities to increase breastfeeding practices in Hispanic mothers (Zhou, Emerson, Husaini, \& Hull, 2014). Lastly, limited studies indicate genetics contributing to obesity susceptibility through biological pathways related to glutamate signaling, insulin 
secretion, energy metabolism, and adipogenesis (Farooqi \& O'Rahilly, 2006; Locke et al., 2015; Shungin et al., 2015; Willer et al., 2009). It has been suggested that epigenetic mechanisms may mediate early environmental exposures during pregnancy with programmed changes in gene expression that may affect fetal/newborn development resulting in offspring obesity and obesity-associated metabolic abnormalities such as metabolic syndrome (Desai, Jellyman, \& Ross, 2015). Their role in the context of neighborhood social and physical factors in segregated environments in Hispanic preschoolers need to be explored.

\section{Discussion}

Despite reports of racial residential segregation within Hispanic communities, Hispanics continue to be underrepresented in studies of neighborhood context, residential segregation, and early childhood and maternal health (Mendez, Hogan, \& Culhane, 2014; Messer, Vinikoor-Imler, \& Laraia, 2012; Kramer \& Hogue, 2009; Oka \& Wong, 2014). The adult population has been the target of recent residential segregation obesity studies (Kershaw \& Albrecht, 2014; Kershaw et al., 2013). Early childhood studies in Hispanic subgroups have centered on maternal prenatal and infant birth weight related outcomes (Acevedo-Garcia, Soobader, \& Berkman, 2007; Osypuk et al., 2010). Based on the limited studies, there is a need for more comprehensive methodological approaches to measure the various dimensions of residential segregation, particularly for Hispanics (Massey, 2012; Massey \& Denton, 1989; Reardon \& O’Sullivan, 2004). There are methodological inconsistencies in the measures used to account for the population group distribution and isolation or interaction within areal units or neighborhoods (Oka \& Wong, 2014). Other factors such as school segregation, neighborhood social, economic, 
and contextual factors need to be addressed in the studies (Britton \& Shin, 2013; Evenson et al., 2009; Vinikoor-Imler, Messer, Evenson, \& Laraia, 2011) (Acevedo-Garcia et al., 2013).

Other limitations of the studies include the use of self-reported maternal data and limited maternal child information from birth certificates (Britton \& Shin, 2013; Debbink \& Bader, 2011). Other interpersonal factors such as maternal prenatal and pre-pregnancy health measures, including pre-pregnancy maternal weight (Messer et al., 2012), and country of natality (Britton \& Shin, 2013) need to be included as these may play a differential role in the birth and weight-related outcomes for children living in segregated environments. Further studies are needed to clarify some of the contradictory findings as they relate to childhood obesity with attention to ethnic subgroups. The limited residential segregation studies have been characterized by the use of multilevel, population-based, cross-sectional, and hierarchical modeling methods using prevalent health outcomes (Osypuk, 2013). Further research including longitudinal studies, modeling the mediation of immediate, proximal, and distal exposures in segregated environments across time based on the age and developmental period of exposure are also needed (Acevedo-Garcia \& Osypuk, 2008; Osypuk, 2013). Merging of individual and neighborhood factors with geographical information system (GIS) techniques to examine spatial segregation in the context of health are also needed (Wen \& Maloney, 2011), especially in the preschool population.

Studies and health promotion efforts addressing obesity trends in Hispanic children must account for organizational and environmental influences on the day-to-day social context of young immigrant families (Lindsay et al., 2009). We need to continue 
the study of nutrition, physical activity, and sedentary behaviors related to overweight and obesity in young children in the context of the ecological model (Institute of Medicine, 2004). The ecological framework may inform our understanding of the effects of racial residential segregation in the various levels that children may be exposed during critical periods such as the early childhood years (Acevedo-Garcia et al., 2013). While no single study can provide the necessary data to understand the complex nature of obesity in children (Cockrell Skinner \& Foster, 2013), rigor in measures to address the neighborhood influences in the food environment on individual dietary and physical activity behavior instruments at the community level are also advocated (Saelens \& Glanz, 2009). Racial residential segregation studies need to be inclusive of cultural values, frameworks, resources, and institutional policies and practices (Griffith, Johnson, Ellis, \& Schulz, 2010). Residential segregation studies in neighborhood local and metropolitan areas are advocated as these may represent a different range of exposures, structural barriers or risks (Osypuk, 2013). Measures such as the neighborhood index of opportunity present an alternative measure of neighborhood-based protective (risk) factors of children's health development (Acevedo-Garcia et al., 2013). Their use in the context of childhood obesity as a health outcome will need to be explored.

\section{Conclusions}

With the persistent disparities in the prevalence of obesity in Hispanic young children and the complex nature of childhood obesity, there is a need for improved conceptual frameworks to examine the contextual factors in the environments in which preschool children live and play. The ecological and life course frameworks should be considered in the study of individual, household, organizational, and community factors 
associated with childhood obesity in race-based segregated environments. This paper conceptualizes the role of the neighborhood social and physical factors as well as organizational, household and/or individual factors as mediators of the correlation between residential segregation and obesity in Hispanic preschoolers. We presented this model as a strategy to guide in the specification of factors in testable analytical models of racial residential segregation and obesity in Hispanic preschool children early in the life course. The model also has implications for other ethnic and migrant minorities living in ethnic enclaves in the United States.

As presented in the model in figure 1 , racial and ethnic residential segregation interacts with inequalities in allocation of resources in Hispanic communities/ neighborhoods. Factors in the neighborhood social and physical environments, as well as household, organizational, and individual factors are likely to mediate the association between residential segregation and child's development of obesity during the preschool period. Policies and programs targeting the nutrition, physical activity, and early life risk factors associated with obesity present significant opportunities to help mitigate the negative effects of residential segregation and inequalities for Hispanic young children. Based on the last two decades of childhood obesity research, we have an increased understanding of the fundamental, intermediate, proximate, and immediate factors associated with obesity during the early childhood period. Research in the context of racial residential segregation shows that while segregated residential areas may be affected by adverse environments limited to physical activity or access to healthy foods, they may represent supportive environments particularly for new immigrants through the social networks, common languages, practices, and norms. 
This review provides practitioners, researchers, and policy makers with important information on factors associated with childhood obesity in the preschool Hispanic population living in segregated, disadvantage areas. In terms of policy, this review highlights the importance of national, state, and local programs in moderating the effects of food insecurity and negative food and physical activity environments for Hispanic preschool minorities. Future studies should examine whether the experience and effects of institutional discrimination in the form of residential segregation vary by developmental age, country of natality, length of residential stay, as well as number of residential moves for young children. It will be important to determine the cumulative effects of these exposures across time, and whether interpersonal and institutional discrimination may interact effecting increased risk of obesity in Hispanics children. This review highlights methodological considerations for future studies of racial residential segregation and intervention work in lower-income, Hispanic children during the early childhood period. Considerations for future studies should extend to the use of longitudinal studies to observe the causal effect of racial/ethnic neighborhood factors on obesity risk. Other factors to account for should include the study of changes within the community with migration/mobility of other ethnic groups across time. State, federal, and community programs and policies should also be studied in their role to offset disparities. 


\section{References}

Acevedo-Garcia, D., \& Osypuk, T. L. (2008). Invited commentary: residential segregation and health--the complexity of modeling separate social contexts. Am J Epidemiol, 168(11), 1255-1258. doi:10.1093/aje/kwn290

Acevedo-Garcia, D., Osypuk, T. L., McArdle, N., \& Williams, D. R. (2008). Toward a policy-relevant analysis of geographic and racial/ethnic disparities in child health. Health Aff (Millwood), 27(2), 321-333. doi:10.1377/hlthaff.27.2.321

Acevedo-Garcia, D., Rosenfeld, L. E., Hardy, E., McArdle, N., \& Osypuk, T. L. (2013). Future directions in research on institutional and interpersonal discrimination and children's health. Am J Public Health, 103(10), 1754-1763. doi:10.2105/ajph.2012.300986

Acevedo-Garcia, D., Soobader, M. J., \& Berkman, L. F. (2007). Low birthweight among US Hispanic/Latino subgroups: the effect of maternal foreign-born status and education. Soc Sci Med, 65(12), 2503-2516. doi:10.1016/j.socscimed.2007.06.033

Asfour, L., Natale, R., Uhlhorn, S., Arheart, K. L., Haney, K., \& Messiah, S. E. (2015). Ethnicity, Household Food Security, and Nutrition and Activity Patterns in Families With Preschool Children. J Nutr Educ Behav, 47(6), 498-505 e491. doi:10.1016/j.jneb.2015.07.003

Baker, E. H., Rendall, M. S., \& Weden, M. M. (2015). Epidemiological Paradox or Immigrant Vulnerability? Obesity Among Young Children of Immigrants. Demography, 52(4), 1295-1320. doi:10.1007/s13524-015-0404-3

Barcelona de Mendoza, V., Harville, E., Theall, K., Buekens, P., \& Chasan-Taber, L. (2016). Acculturation and Intention to Breastfeed among a Population of Predominantly Puerto Rican Women. Birth, 43(1), 78-85. doi:10.1111/birt.12199

Benjamin Neelon, S. E., Taveras, E. M., Ostbye, T., \& Gillman, M. W. (2014). Preventing obesity in infants and toddlers in child care: results from a pilot randomized controlled trial. Matern Child Health J, 18(5), 1246-1257. doi:10.1007/s10995-013-1359-X

Bjerregaard, L. G., Rasmussen, K. M., Michaelsen, K. F., Skytthe, A., Mortensen, E. L., Baker, J. L., \& Sorensen, T. I. (2014). Effects of body size and change in body size from infancy through childhood on body mass index in adulthood. Int $J$ Obes (Lond), 38(10), 1305-1311. doi:10.1038/ijo.2014.108

Boney, C. M., Verma, A., Tucker, R., \& Vohr, B. R. (2005). Metabolic syndrome in childhood: association with birth weight, maternal obesity, and gestational diabetes mellitus. Pediatrics, 115(3), e290-296. doi:10.1542/peds.2004-1808 
Borjas, G. (1998). To Ghetto or Not to Ghetto: Ethnicity and Residential Segregation. Journal of Urban Economics 44, no. 2 (1998): 228 (26 pages), 44(4), 228-253

Boutelle, K., Fulkerson, J. A., Neumark-Sztainer, D., \& Story, M. (2004). Mothers' perceptions of their adolescents' weight status: are they accurate? Obes Res, 12(11), 1754-1757. doi:10.1038/oby.2004.217

Bower, K. M., Thorpe, R. J., Jr., Rohde, C., \& Gaskin, D. J. (2014). The intersection of neighborhood racial segregation, poverty, and urbanicity and its impact on food store availability in the United States. Prev Med, 58, 33-39. doi:10.1016/j.ypmed.2013.10.010

Brewer, M., \& Kimbro, R. T. (2014). Neighborhood context and immigrant children's physical activity. Soc Sci Med, 116, 1-9. doi:10.1016/j.socscimed.2014.06.022

Britton, M. L., \& Shin, H. (2013). Metropolitan residential segregation and very preterm birth among African American and Mexican-origin women. Soc Sci Med, 98, 3745. doi:10.1016/j.socscimed.2013.08.039

Brown, C. L., Halvorson, E. E., Cohen, G. M., Lazorick, S., \& Skelton, J. A. (2015). Addressing Childhood Obesity: Opportunities for Prevention. Pediatr Clin North Am, 62(5), 1241-1261. doi:10.1016/j.pcl.2015.05.013

Brownson, R. C., Kemner, A. L., \& Brennan, L. K. (2015). Applying a mixed-methods evaluation to Healthy Kids, Healthy Communities. J Public Health Manag Pract, 21 Suppl 3, S16-26. doi:10.1097/phh.0000000000 000233

Chang, J. J., Tabet, M., Elder, K., Kiel, D. W., \& Flick, L. H. (2016). Racial/Ethnic Differences in the Correlates of Mental Health Services Use among Pregnant Women with Depressive Symptoms. Matern Child Health J. doi:10.1007/s10995016-2005-1

Chaparro, M. P., Langellier, B. A., Kim, L. P., \& Whaley, S. E. (2011). Predictors of accurate maternal perception of their preschool child's weight status among Hispanic WIC participants. Obesity (Silver Spring), 19(10), 2026-2030. doi:10.1038/oby.2011.105

Chaparro, M. P., Whaley, S. E., Crespi, C. M., Koleilat, M., Nobari, T. Z., Seto, E., \& Wang, M. C. (2014). Influences of the neighbourhood food environment on adiposity of low-income preschool-aged children in Los Angeles County: a longitudinal study. J Epidemiol Community Health, 68(11), 1027-1033. doi:10.1136/jech-2014-204034

Chen, H. J., \& Wang, Y. (2016). Changes in the Neighborhood Food Store Environment and Children's Body Mass Index at Peripuberty in the United States. J Adolesc Health, 58(1), 111-118. doi:10.1016/j.jadohealth.2015. 09.012 
Chuang, R. J., Sharma, S., Skala, K., \& Evans, A. (2013). Ethnic differences in the home environment and physical activity behaviors among low-income, minority preschoolers in Texas. Am J Health Promot, 27(4), 270-278. doi:10.4278/ajhp.110427-QUAN-171

Chung, L. H., Gregorich, S. E., Armitage, G. C., Gonzalez-Vargas, J., \& Adams, S. H. (2014). Sociodemographic disparities and behavioral factors in clinical oral health status during pregnancy. Community Dent Oral Epidemiol, 42(2), 151-159. doi:10.1111/cdoe.12075

Cockrell Skinner, A., \& Foster, E. M. (2013). Systems science and childhood obesity: a systematic review and new directions. J Obes, 2013, 129193. doi:10.1155/2013/129193

Coleman-Jensen, A., Nord, M., Andrews, M., \& Carlson, S. (2011). Household Food Security in the United States, 2010: Economic Research Report No. (ERR-125). Washington, DC: Economic Research Division.

Corral, I., Landrine, H., \& Zhao, L. (2014). Residential segregation and obesity among a national sample of Hispanic adults. J Health Psychol, 19(4), 503-508. doi:10.1177/1359105312474912

Daniel, M., Moore, S., \& Kestens, Y. (2008). Framing the biosocial pathways underlying associations between place and cardiometabolic disease. Health Place, 14(2), 117-132. doi:10.1016/j.healthplace.2007.05.003

Davison, K. K., \& Birch, L. L. (2001). Childhood overweight: a contextual model and recommendations for future research. Obes Rev, 2(3), 159-171.

Davidson, A. J., McCormick, E. V., Dickinson, L. M., Haemer, M. A., Knierim, S. D., \& Hambidge, S. J. (2014). Population-level obesity surveillance: monitoring childhood body mass index z-score in a safety-net system. Acad Pediatr, 14(6), 632-638. doi:10.1016/j.acap.2014.06.007

Debbink, M. P., \& Bader, M. D. (2011). Racial residential segregation and low birth weight in Michigan's metropolitan areas. Am J Public Health, 101(9), 1714-1720. doi:10.2105/ajph.2011.300152

Desai, M., Jellyman, J. K., \& Ross, M. G. (2015). Epigenomics, gestational programming and risk of metabolic syndrome. Int J Obes (Lond), 39(4), 633-641. doi:10.1038/ijo.2015.13

Dev, D. A., McBride, B. A., Fiese, B. H., Jones, B. L., \& Cho, H. (2013). Risk Factors for Overweight/Obesity in Preschool Children: An Ecological Approach. Childhood Obesity, 9(5), 399-408. doi:http://doi.org/10.1089/chi.2012.0150 
Dixon, B., Pena, M. M., \& Taveras, E. M. (2012). Lifecourse approach to racial/ethnic disparities in childhood obesity. Adv Nutr, 3(1), 73-82.

doi:10.3945/an.111.000919

Dozier, A. M., \& McKee, K. S. (2011). State breastfeeding worksite statutes....breastfeeding rates..and. Breastfeed Med, 6, 319-324. doi:10.1089/bfm.2011.0082

Evans, A., Chow, S., Jennings, R., Dave, J., Scoblick, K., Sterba, K. R., \& Loyo, J. (2011). Traditional foods and practices of Spanish-speaking Latina mothers influence the home food environment: implications for future interventions. $J \mathrm{Am}$ Diet Assoc, 111(7), 1031-1038. doi:10.1016/j.jada.2011.04.007

Evenson, K. R., Sotres-Alvarez, D., Herring, A. H., Messer, L., Laraia, B. A., \& Rodriguez, D. A. (2009). Assessing urban and rural neighborhood characteristics using audit and GIS data: derivation and reliability of constructs. Int J Behav Nutr Phys Act, 6, 44. doi:10.1186/1479-5868-6-44

Elhakeem A, Hardy R, Bann D, Caleyachetty R, Cosco TD, Hayhoe RP, Muthuri SG, Wilson R, Cooper R. 2016). Intergenerational social mobility and leisuretime physical activity in adulthood: a systematic review. J Epidemiol Community Health., Dec 15. pii: jech-2016-208052. doi: 10.1136/jech-2016-208052.

Elder, J. P., Arredondo, E. M., Campbell, N., Baquero, B., Duerksen, S., Ayala, G., . . . McKenzie, T. (2010). Individual, family, and community environmental correlates of obesity in Latino elementary school children. J Sch Health, 80(1), 20-30; quiz 53-25. doi:10.1111/j.1746-1561.2009.00462.x

Farooqi, S., \& O'Rahilly, S. (2006). Genetics of obesity in humans. Endocr Rev, 27(7), 710-718. doi:10.1210/er.2006-0040

Freedman, D. S., Mei, Z., Srinivasan, S. R., Berenson, G. S., \& Dietz, W. H. (2007). Cardiovascular risk factors and excess adiposity among overweight children and adolescents: the Bogalusa Heart Study. J Pediatr, 150(1), 12-17.e12. doi:10.1016/j.jpeds.2006.08.042

Galobardes, B., Smith, G. D., \& Lynch, J. W. (2006). Systematic review of the influence of childhood socioeconomic circumstances on risk for cardiovascular disease in adulthood. Ann Epidemiol, 16(2), 91-104. doi:10.1016/j.annepidem.2005.06.053

Gauthier, K. I., \& Gance-Cleveland, B. (2015). Hispanic Parental Perceptions of Child Weight in Preschool-Aged Children: An Integrated Review. Child Obes, 11(5), 549-559. doi:10.1089/chi.2014.0152 
Gauthier, K. I., \& Gance-Cleveland, B. (2016). Hispanic parents' perceptions of their preschool children's weight status. J Spec Pediatr Nurs, 21(2), 84-93. doi:10.1111/jspn.12143

Glick, J. E., \& Yabiku, S. T. (2015). A moving paradox: a binational view of obesity and residential mobility. J Immigr Minor Health, 17(2), 489-497. doi:10.1007/s10903014-0030-y

Gordon-Larsen, P., Harris, K. M., Ward, D. S., \& Popkin, B. M. (2003). Acculturation and overweight-related behaviors among Hispanic immigrants to the US: the National Longitudinal Study of Adolescent Health. Soc Sci Med, 57(11), 20232034.

Goulao, B., Santos, O., \& Carmo, I. (2015). The impact of migration on body weight: a review. Cad Saude Publica, 31(2), 229-245.

Gray, V. B., Cossman, J. S., Dodson, W. L., \& Byrd, S. H. (2005). Dietary acculturation of Hispanic immigrants in Mississippi. Salud Publica Mex, 47(5), 351-360.

Griffith, D. M., Johnson, J., Ellis, K. R., \& Schulz, A. J. (2010). Cultural context and a critical approach to eliminating health disparities. Ethn Dis, 20(1), 71-76.

Gundersen, C., Lohman, B. J., Garasky, S., Stewart, S., \& Eisenmann, J. (2008). Food security, maternal stressors, and overweight among low-income US children: results from the National Health and Nutrition Examination Survey (1999-2002). Pediatrics, 122(3), e529-540. doi:10.1542/peds.2008-0556

Hajat, A., Hsia, C., \& O'Neill, M. S. (2015). Socioeconomic Disparities and Air Pollution Exposure: a Global Review. Curr Environ Health Rep, 2(4), 440-450. doi:10.1007/s40572-015-0069-5

Han, J. C., Lawlor, D. A., \& Kimm, S. Y. (2010). Childhood obesity. Lancet, 375(9727), 1737-1748. doi:10.1016/s0140-6736(10)60171-7

Haughton, C. F., Wang, M. L., \& Lemon, S. C. (2016). Racial/Ethnic Disparities in Meeting 5-2-1-0 Recommendations among Children and Adolescents in the United States. J Pediatr. doi:10.1016/j.jpeds.2016.03.055

Hosler, A. S., Michaels, I. H., \& Buckenmeyer, E. M. (2016). Food Shopping Venues, Neighborhood Food Environment, and Body Mass Index Among Guyanese, Black, and White Adults in an Urban Community in the US. J Nutr Educ Behav, 48(6), 361-368.e361. doi:10.1016/j.jneb.2016.03.003

Houghton, F., Kelleher, K., \& Duncan, B. (2003). Migration, mobility and the exposure fallacy: an issue for New Zealand. N Z Med J, 116(1180), U572. 
Iceland, J., \& Scopilliti, M. (2008). Immigrant residential segregation in U.S. metropolitan areas, 1990-2000. Demography, 45(1), 79-94.

Innella, N., Breitenstein, S., Hamilton, R., Reed, M., \& McNaughton, D. B. (2015). Determinants of Obesity in the Hispanic Preschool Population: An Integrative Review. Public Health Nurs. doi:10.1111/phn.12215

Institute of Medicine (IOM) (2004). Preventing Childhood Obesity: Health in the Balance. Washington, D.C.: Institute of Medicine.

Jaskiewicz, L., Dombrowski, R. D., Drummond, H. M., Barnett, G. M., Mason, M., \& Welter, C. (2013). Partnering with community institutions to increase access to healthful foods across municipalities. Prev Chronic Dis, 10, E167. doi:10.5888/pcd10.130011

Jones-Webb, R., \& Wall, M. (2008). Neighborhood racial/ethnic concentration, social disadvantage, and homicide risk: an ecological analysis of 10 U.S. cities. J Urban Health, 85(5), 662-676. doi:10.1007/s11524-008-9302-y

Jokela, M. (2014). Are neighborhood health associations causal? A 10-year prospective cohort study with repeated measurements. Am J Epidemiol, 180(8), 776-784. doi:10.1093/aje/kwu233

Jones, A. (2015). Residential instability and obesity over time: the role of the social and built environment. Health Place, 32, 74-82.

doi:10.1016/j.healthplace.2015.01.001

Johnson, W., Kuh, D., Tikhonoff, V., Charakida, M., Woodside, J., Whincup, P., . . . Hardy, R. (2014). Body mass index and height from infancy to adulthood and carotid intima-media thickness at 60 to 64 years in the 1946 British Birth Cohort Study. Arterioscler Thromb Vasc Biol, 34(3), 654-660.

doi:10.1161/atvbaha.113.302572

Kelly, Y., Becares, L., \& Nazroo, J. (2013). Associations between maternal experiences of racism and early child health and development: findings from the UK Millennium Cohort Study. J Epidemiol Community Health, 67(1), 35-41. doi:10.1136/jech-2011-200814

Kershaw, K. N., \& Albrecht, S. S. (2014). Metropolitan-level ethnic residential segregation, racial identity, and body mass index among U.S. Hispanic adults: a multilevel cross-sectional study. BMC Public Health, 14, 283. doi:10.1186/14712458-14-283 
Kershaw, K. N., Albrecht, S. S., \& Carnethon, M. R. (2013). Racial and ethnic residential segregation, the neighborhood socioeconomic environment, and obesity among blacks and Mexican Americans. Am J Epidemiol, 177(4), 299-309. doi:10.1093/aje/kws372

Kim, Y. A., Collins, T. W., \& Grineski, S. E. (2014). Neighborhood context and the Hispanic health paradox: differential effects of immigrant density on childrens wheezing by poverty, nativity and medical history. Health Place, 27, 1-8. doi:10.1016/j.healthplace.2014.01.006

Kimbro, R. T., \& Denney, J. T. (2013). Neighborhood context and racial/ethnic differences in young children's obesity: structural barriers to interventions. Soc Sci Med, 95, 97-105. doi:10.1016/j.socscimed.2012.09.032

Korenman, S., Abner, K. S., Kaestner, R., \& Gordon, R. A. (2013). The Child and Adult Care Food Program and the Nutrition of Preschoolers. Early Child Res Q, 28(2), 325-336. doi:10.1016/j.ecresq.2012.07.007

Kramer, M. R., \& Hogue, C. R. (2009). Is segregation bad for your health? Epidemiol Rev, 31, 178-194. doi:10.1093/epirev/mxp001

Krivo, L. J., Peterson, R. D., \& Kuhl, D. C. (2009). Segregation, racial structure, and neighborhood violent crime. AJS, 114(6), 1765-1802.

Larson, N., Story, M. T., \& Nelson, M. C. (2009). Neighborhood environments: disparities in access to healthy foods in the U.S. Am J Prev Med, 36(1), 74-81. doi:10.1016/j.amepre.2008.09.025

Laurent, O., Hu, J., Li, L., Cockburn, M., Escobedo, L., Kleeman, M. J., \& Wu, J. (2014). Sources and contents of air pollution affecting term low birth weight in Los Angeles County, California, 2001-2008. Environ Res, 134, 488-495. doi:10.1016/j.envres.2014.05.003

Lind, J. N., Perrine, C. G., Li, R., Scanlon, K. S., \& Grummer-Strawn, L. M. (2014). Racial disparities in access to maternity care practices that support breastfeeding United States, 2011. MMWR Morb Mortal Wkly Rep, 63(33), 725-728.

Lindberg, S. M., DeBoth, A., \& Anderson, C. K. (2016). Effect of a Best Practice Alert on Gestational Weight Gain, Health Services, and Pregnancy Outcomes. Matern Child Health J. doi:10.1007/s10995-016-2052-7

Lindsay, A. C., Salkeld, J. A., Greaney, M. L., \& Sands, F. D. (2015). Latino family childcare providers' beliefs, attitudes, and practices related to promotion of healthy behaviors among preschool children: a qualitative study. J Obes, 2015, 409742. doi:10.1155/2015/409742 
Lindsay, A. C., Sussner, K. M., Greaney, M. L., \& Peterson, K. E. (2009). Influence of social context on eating, physical activity, and sedentary behaviors of Latina mothers and their preschool-age children. Health Educ Behav, 36(1), 81-96. doi:10.1177/1090198107308375

Lindsay, A. C., Sussner, K. M., Greaney, M. L., \& Peterson, K. E. (2011). Latina mothers' beliefs and practices related to weight status, feeding, and the development of child overweight. Public Health Nurs, 28(2), 107-118. doi:10.1111/j.1525-1446.2010.00906.x

Locke, A. E., Kahali, B., Berndt, S. I., Justice, A. E., Pers, T. H., Day, F. R., . . . Speliotes, E. K. (2015). Genetic studies of body mass index yield new insights for obesity biology. Nature, 518(7538), 197-206. doi:10.1038/nature14177

Mabli, J., \& Worthington, J. (2014). Supplemental nutrition assistance program participation and child food security. Pediatrics, 133(4), 610-619. doi:10.1542/peds.2013-2823

Mangini, L. D., Hayward, M. D., Dong, Y. Q., \& Forman, M. R. (2015). Household Food Insecurity is Associated with Childhood Asthma. J Nutr, 145(12), 2756-2764. doi:10.3945/jn.115.215939

Massey, D. S. (2012). Reflections on the Dimensions of Segregation. Soc Forces, 91(1), 39-43. doi:10.1093/sf/sos118

Massey, D. S., \& Denton, N. A. (1989). Hypersegregation in U.S. metropolitan areas: Black and Hispanic segregation along five dimensions. Demography, 26(3), 373391.

McKinney, C. O., Hahn-Holbrook, J., Chase-Lansdale, P. L., Ramey, S. L., Krohn, J., Reed-Vance, M., ... Shalowitz, M. U. (2016). Racial and Ethnic Differences in Breastfeeding. Pediatrics. doi:10.1542/peds.2015-2388

Mendez, D. D., Hogan, V. K., \& Culhane, J. F. (2014). Institutional racism, neighborhood factors, stress, and preterm birth. Ethn Health, 19(5), 479-499. doi:10.1080/13557858.2013.846300

Mendoza, J. A., McLeod, J., Chen, T. A., Nicklas, T. A., \& Baranowski, T. (2014). Correlates of adiposity among Latino preschool children. J Phys Act Health, 11(1), 195-198. doi:10.1123/jpah.2012-0018

Messer, L. C., Vinikoor-Imler, L. C., \& Laraia, B. A. (2012). Conceptualizing neighborhood space: consistency and variation of associations for neighborhood factors and pregnancy health across multiple neighborhood units. Health Place, 18(4), 805-813. doi:10.1016/j.healthplace.2012.03.012 
Messiah, S. E., Arheart, K. L., Natale, R. A., Hlaing, W. M., Lipshultz, S. E., \& Miller, T. L. (2012). BMI, waist circumference, and selected cardiovascular disease risk factors among preschool-age children. Obesity (Silver Spring), 20(9), 1942-1949. doi:10.1038/oby.2011.353

Messiah, S. E., Asfour, L., Arheart, K. L., Selem, S. M., Uhlhorn, S. B., \& Natale, R. (2015). Relationship between parent demographic characteristics, perinatal and early childhood behaviors, and body mass index among preschool-age children. $J$ Immigr Minor Health, 17(2), 414-421. doi:10.1007/s10903-014-0079-7

Morland, K., Wing, S., Diez Roux, A., \& Poole, C. (2002). Neighborhood characteristics associated with the location of food stores and food service places. Am J Prev Med, 22(1), 23-29.

Nader, P. R., O'Brien, M., Houts, R., Bradley, R., Belsky, J., Crosnoe, R., . . . Susman, E. J. (2006). Identifying risk for obesity in early childhood. Pediatrics, 118(3), e594601. doi:10.1542/peds.2005-2801

Ncube, C. N., Enquobahrie, D. A., Albert, S. M., Herrick, A. L., \& Burke, J. G. (2016). Association of neighborhood context with offspring risk of preterm birth and low birthweight: A systematic review and meta-analysis of population-based studies. Soc Sci Med, 153, 156-164. doi:10.1016/j.socscimed.2016.02.014

Nobari, T. Z., Wang, M. C., Chaparro, M. P., Crespi, C. M., Koleilat, M., \& Whaley, S. E. (2013). Immigrant enclaves and obesity in preschool-aged children in Los Angeles County. Soc Sci Med, 92, 1-8. doi:10.1016/j.socscimed.2013.05.019

Nyarko, K. A., \& Wehby, G. L. (2012). Residential segregation and the health of African-American infants: does the effect vary by prevalence? Matern Child Health J, 16(7), 1491-1499. doi:10.1007/s10995-011-0915-5

O'Connor, T. M., Cerin, E., Lee, R. E., Parker, N., Chen, T. A., Hughes, S. O., . . . Baranowski, T. (2014). Environmental and cultural correlates of physical activity parenting practices among Latino parents with preschool-aged children: Ninos Activos. BMC Public Health, 14, 707. doi:10.1186/1471-2458-14-707

Ogden, C. L., Carroll, M. D., Kit, B. K., \& Flegal, K. M. (2014). Prevalence of childhood and adult obesity in the United States, 2011-2012. JAMA, 311(8), 806-814. doi:10.1001/jama.2014.732

Ohri-Vachaspati, P., Lloyd, K., Delia, D., Tulloch, D., \& Yedidia, M. J. (2013). A closer examination of the relationship between children's weight status and the food and physical activity environment. Prev Med, 57(3), 162-167. doi:10.1016/j.ypmed.2013.05.009 
Oka, M., \& Wong, D. W. (2014). Capturing the two dimensions of residential segregation at the neighborhood level for health research. Front Public Health, 2, 118. doi:10.3389/fpubh.2014.00118

Osypuk, T. L. (2013). Invited commentary: integrating a life-course perspective and social theory to advance research on residential segregation and health. Am J Epidemiol, 177(4), 310-315. doi:10.1093/aje/kws371

Osypuk, T. L., Bates, L. M., \& Acevedo-Garcia, D. (2010). Another Mexican birthweight paradox? The role of residential enclaves and neighborhood poverty in the birthweight of Mexican-origin infants. Soc Sci Med, 70(4), 550-560. doi:10.1016/j.socscimed.2009.10.034

Osypuk, T. L., Diez Roux, A. V., Hadley, C., \& Kandula, N. R. (2009). Are immigrant enclaves healthy places to live? The Multi-ethnic Study of Atherosclerosis. Soc Sci Med, 69(1), 110-120. doi:10.1016/j.socscimed.2009.04.010

Papas, M. A., Trabulsi, J. C., Dahl, A., \& Dominick, G. (2015). Food Insecurity Increases the Odds of Obesity Among Young Hispanic Children. J Immigr Minor Health. doi:10.1007/s10903-015-0275-0

Partridge, S., Balayla, J., Holcroft, C. A., \& Abenhaim, H. A. (2012). Inadequate prenatal care utilization and risks of infant mortality and poor birth outcome: a retrospective analysis of 28,729,765 U.S. deliveries over 8 years. Am J Perinatol, 29(10), 787-793. doi:10.1055/s-0032-1316439

Pearson, N., Biddle, S. J., \& Gorely, T. (2009). Family correlates of fruit and vegetable consumption in children and adolescents: a systematic review. Public Health Nutr, 12(2), 267-283. doi:10.1017/s1368980008002589

Perez-Escamilla, R., \& Putnik, P. (2007). The role of acculturation in nutrition, lifestyle, and incidence of type 2 diabetes among Latinos. J Nutr, 137(4), 860-870.

Pudrovska, T., Logan, E. S., \& Richman, A. (2014). Early-life social origins of later-life body weight: the role of socioeconomic status and health behaviors over the life course. Soc Sci Res, 46, 59-71. doi:10.1016/j.ssresearch.2014.02.007

Puhl, R. M., \& Latner, J. D. (2007). Stigma, obesity, and the health of the nation's children. Psychol Bull, 133(4), 557-580. doi:10.1037/0033-2909.133.4.557

Pulgaron, E. R. (2013). Childhood obesity: a review of increased risk for physical and psychological comorbidities. Clin Ther, 35(1), A18-32.

doi:10.1016/j.clinthera.2012.12.014 
Ranchod, Y. K., Headen, I. E., Petito, L. C., Deardorff, J. K., Rehkopf, D. H., \& Abrams, B. F. (2016). Maternal Childhood Adversity, Prepregnancy Obesity, and Gestational Weight Gain. Am J Prev Med, 50(4), 463-469. doi:10.1016/j.amepre.2015.08.032

Rassin, D. K., Markides, K. S., Baranowski, T., Richardson, C. J., Mikrut, W. D., \& Bee, D. E. (1994). Acculturation and the initiation of breastfeeding. J Clin Epidemiol, 47(7), 739-746.

Reardon, S. F., \& O’Sullivan, D. (2004). Measures of Spatial Segregation. Sociological Methodology, 34, 121-162. doi:10.1111/j.0081-1750.2004.00150.x

Reid, J. L., \& Kagan, S. L. (2015). A better start. Why classroom diversity matters in early education. . Retrieved from Ritchie, L. D., Boyle, M., Chandran, K., Spector, P., Whaley, S. E., James, P., . . Crawford, P. (2012). Participation in the child and adult care food program is associated with more nutritious foods and beverages in child care. Child Obes, 8(3), 224-229. doi:10.1089/chi.2011.0061

Ravensbergen L, Buliung R, Wilson K, Faulkner G. (2016). "Socioeconomic inequalities in children's accessibility to food retailing: Examining the roles of mobility and time". Soc Sci Med., Mar;153:81-9. doi:

10.1016/j.socscimed.2016.01.030.

Ritchie, L. D., Sharma, S., Gildengorin, G., Yoshida, S., Braff-Guajardo, E., \& Crawford, P. (2015). Policy improves what beverages are served to young children in child care. J Acad Nutr Diet, 115(5), 724-730. doi:10.1016/j.jand.2014.07.019

Rossen, L. M. (2014). Neighbourhood economic deprivation explains racial/ethnic disparities in overweight and obesity among children and adolescents in the U.S.A. J Epidemiol Community Health, 68(2), 123-129. doi:10.1136/jech-2012202245

Ruiz, R., Gesell, S. B., Buchowski, M. S., Lambert, W., \& Barkin, S. L. (2011). The relationship between hispanic parents and their preschool-aged children's physical activity. Pediatrics, 127(5), 888-895. doi:10.1542/peds.2010-1712

Rundle, A., Hoepner, L., Hassoun, A., Oberfield, S., Freyer, G., Holmes, D., . . . Whyatt, R. (2012). Association of childhood obesity with maternal exposure to ambient air polycyclic aromatic hydrocarbons during pregnancy. Am J Epidemiol, 175(11), 1163-1172. doi:10.1093/aje/kwr455

Sacco, M. R., de Castro, N. P., Euclydes, V. L., Souza, J. M., \& Rondo, P. H. (2013). Birth weight, rapid weight gain in infancy and markers of overweight and obesity in childhood. Eur J Clin Nutr, 67(11), 1147-1153. doi:10.1038/ejcn.2013.183 
Saelens, B. E., \& Glanz, K. (2009). Work group I: Measures of the food and physical activity environment: instruments. Am J Prev Med, 36(4 Suppl), S166-170. doi:10.1016/j.amepre.2009.01.006

Scanlon, K., Grummer-Strawn, L. M., Li, R., \& Chen, J. (2010). Racial and ethnic differences in breastfeeding initiation and duration, by state - National Immunization Survey, United States, 2004-2008. (1545-861X (Electronic).

Schulz, A. J., Kannan, S., Dvonch, J. T., Israel, B. A., Allen, A., 3rd, James, S. A., . . . Lepkowski, J. (2005). Social and physical environments and disparities in risk for cardiovascular disease: the healthy environments partnership conceptual model. Environ Health Perspect, 113(12), 1817-1825.

Schulz, A. J., Mentz, G., Lachance, L., Johnson, J., Gaines, C., \& Israel, B. A. (2012). Associations between socioeconomic status and allostatic load: effects of neighborhood poverty and tests of mediating pathways. Am J Public Health, 102(9), 1706-1714. doi:10.2105/ajph.2011.300412

Sekhobo, J. P., Edmunds, L. S., Dalenius, K., Jernigan, J., Davis, C. F., Giddings, M., . . . Kettel Khan, L. (2014). Neighborhood disparities in prevalence of childhood obesity among low-income children before and after implementation of New York City child care regulations. Prev Chronic Dis, 11, E181. doi:10.5888/pcd11.140152

Sherry, B., McDivitt, J., Birch, L. L., Cook, F. H., Sanders, S., Prish, J. L., . . Scanlon, K. S. (2004). Attitudes, practices, and concerns about child feeding and child weight status among socioeconomically diverse white, Hispanic, and AfricanAmerican mothers. J Am Diet Assoc, 104(2), 215-221. doi:10.1016/j.jada.2003.11.012

Shungin, D., Winkler, T. W., Croteau-Chonka, D. C., Ferreira, T., Locke, A. E., Magi, R., . . Mohlke, K. L. (2015). New genetic loci link adipose and insulin biology to body fat distribution. Nature, 518(7538), 187-196. doi:10.1038/nature14132

Singh, G. K., Kogan, M. D., \& Dee, D. L. (2007). Nativity/immigrant status, race/ethnicity, and socioeconomic determinants of breastfeeding initiation and duration in the United States, 2003. Pediatrics, 119 Suppl 1, S38-46. doi:10.1542/peds.2006-2089G

Sobal, J. (2001). Commentary: globalization and the epidemiology of obesity. Int $J$ Epidemiol, 30(5), 1136-1137.

Spatz, D. L. (2014). Preventing obesity starts with breastfeeding. J Perinat Neonatal Nurs, 28(1), 41-50. doi:10.1097/jpn.0000000000000009 
Stang, J., \& Bayerl, C. T. (2010). Position of the American Dietetic Association: child and adolescent nutrition assistance programs. J Am Diet Assoc, 110(5), 791-799.

Stromgren, M., Tammaru, T., Danzer, A. M., van Ham, M., Marcinczak, S., Stjernstrom, O., \& Lindgren, U. (2014). Factors shaping workplace segregation between natives and immigrants. Demography, 51(2), 645-671. doi:10.1007/s13524-0130271-8

Suglia, S. F., Shelton, R. C., Hsiao, A., Wang, Y. C., Rundle, A., \& Link, B. G. (2016). Why the Neighborhood Social Environment Is Critical in Obesity Prevention. $J$ Urban Health. doi:10.1007/s11524-015-0017-6

Szostak-Wegierek, D., \& Szamotulska, K. (2011). Fetal development and risk of cardiovascular diseases and diabetes type 2 in adult life. Med Wieku Rozwoj, 15(3), 203-215.

Tandon, S. D., Cluxton-Keller, F., Colon, L., Vega, P., \& Alonso, A. (2013). Improved adequacy of prenatal care and healthcare utilization among low-income Latinas receiving group prenatal care. J Womens Health (Larchmt), 22(12), 1056-1061. doi:10.1089/jwh.2013.4352

Tovar, A., Mena, N. Z., Risica, P., Gorham, G., \& Gans, K. M. (2015). Nutrition and Physical Activity Environments of Home-Based Child Care: What Hispanic Providers Have to Say. Child Obes. doi:10.1089/chi.2015.0040

Vangeepuram, N., Mervish, N., Galvez, M. P., Brenner, B., \& Wolff, M. S. (2012). Dietary and physical activity behaviors of New York City children from different ethnic minority subgroups. Acad Pediatr, 12(6), 481-488. doi:10.1016/j.acap.2012.06.014

Vinikoor-Imler, L. C., Davis, J. A., Meyer, R. E., Messer, L. C., \& Luben, T. J. (2014). Associations between prenatal exposure to air pollution, small for gestational age, and term low birthweight in a state-wide birth cohort. Environ Res, 132, 132-139. doi:10.1016/j.envres.2014.03.040

Vinikoor-Imler, L. C., Messer, L. C., Evenson, K. R., \& Laraia, B. A. (2011). Neighborhood conditions are associated with maternal health behaviors and pregnancy outcomes. Soc Sci Med, 73(9), 1302-1311. doi:10.1016/j.socscimed.2011.08.012

Ward, S., Belanger, M., Donovan, D., \& Carrier, N. (2015). Systematic review of the relationship between childcare educators' practices and preschoolers' physical activity and eating behaviours. Obes Rev. doi:10.1111/obr.12315

Weedn, A. E., Hale, J. J., Thompson, D. M., \& Darden, P. M. (2014). Trends in obesity prevalence and disparities among low-income children in Oklahoma, 2005-2010. Child Obes, 10(4), 318-325. doi:10.1089/chi.2014.0022 
Wen, M., \& Maloney, T. N. (2011). Latino residential isolation and the risk of obesity in Utah: the role of neighborhood socioeconomic, built-environmental, and subcultural context. J Immigr Minor Health, 13(6), 1134-1141. doi:10.1007/s10903-011-9439-8

Willer, C. J., Speliotes, E. K., Loos, R. J., Li, S., Lindgren, C. M., Heid, I. M., . . . Hirschhorn, J. N. (2009). Six new loci associated with body mass index highlight a neuronal influence on body weight regulation. Nat Genet, 41(1), 25-34. doi:10.1038/ng.287

Williams, D., \& Collins, C. ( 2001). Racial residential segregation: a fundamental cause of racial disparities in health. . Public Health Reports, 116(5), 404-416.

Xie, Y., \& Gough, M. (2011). Ethnic enclaves and the earnings of immigrants. Demography, 48(4), 1293-1315. doi:10.1007/s13524-011-0058-8

Yang, T. C., Shoff, C., Noah, A. J., Black, N., \& Sparks, C. S. (2014). Racial segregation and maternal smoking during pregnancy: a multilevel analysis using the racial segregation interaction index. Soc Sci Med, 107, 26-36.

doi:10.1016/j.socscimed.2014.01.030

Yoong, S. L., Finch, M., Nathan, N., Wiggers, J., Lecathelinais, C., Jones, J., . . . Wolfenden, L. (2016). A longitudinal study assessing childcare services' adoption of obesity prevention policies and practices. J Paediatr Child Health. doi:10.1111/jpc.13252

Zenk, S. N., Mentz, G., Schulz, A. J., Johnson-Lawrence, V., \& Gaines, C. R. (2016). Longitudinal Associations Between Observed and Perceived Neighborhood Food Availability and Body Mass Index in a Multiethnic Urban Sample. Health Educ Behav. doi:10.1177/1090198116644150

Zenk, S. N., Schulz, A. J., Israel, B. A., James, S. A., Bao, S., \& Wilson, M. L. (2005). Neighborhood racial composition, neighborhood poverty, and the spatial accessibility of supermarkets in metropolitan Detroit. Am J Public Health, 95(4), 660-667. doi:10.2105/ajph.2004.042150

Zhou, Y. E., Emerson, J. S., Husaini, B. A., \& Hull, P. C. (2014). Association of infant feeding with adiposity in early childhood in a WIC sample. $J$ Health Care Poor Underserved, 25(4), 1542-1551. doi:10.1353/hpu.2014.0181 


\title{
MANUSCRIPT 2
}

\section{State Mandated Nutrition, Physical Activity, and Screen-time Policies in Child Care Centers}

\begin{abstract}
BACKGROUND: The child care center (CCC) environment presents opportunities for healthy weight promotion in preschoolers. AIM: To examine: (1) current state of CCC adherence to nutrition, physical activity and screen-time legislative regulations, and differences in their adherence by center socioeconomic position (SEP) (low, middle, high) in Miami-Dade County. METHODS: The following measures were collected in 34 CCC: (1) the Environment and Policy Assessment and Observation (EPAO) tool to evaluate nutrition, physical activity, and screen-time practices during one school day. RESULTS: Twenty-five of the centers (73.5\%) were participants of the Child and Adult Care Food Program. Almost 80\% of the centers adhered to serving low/fat-free milk to children older than 2-years-old. Only 34.5\% served vegetables and 75.9\% served whole fruits during meals/snacks. Ninety-four percent of the centers had quiet and active play incorporated into their daily routines. All centers adhered to the two-hour screen-time limit for children older than 2-years-old. Low and middle-SEP centers fared better in the serving of fruits, vegetables, and low fat/ fat free milk. The centers averaged one hour in outdoor play regardless of SEP. High-SEP centers had no TV or screen-time during day of observation. CONCLUSIONS: CCC practices highlight opportunities for improvement in nutrition, physical activity, and screen-time practices in the prevention of overweight in early childhood.
\end{abstract}

KEYWORDS: child care, nutrition, physical activity, screen-time, childhood obesity 


\section{Introduction}

In the United States (U.S.), the prevalence of obesity in 2-19-year-old children has more than tripled over the last thirty years and has remained unchanged at $17 \%$ for the past decade or so (Ogden et al., 2016). Among children 2-to-5 years-old, obesity increased from $7.2 \%$ in $1988-1994$ to $13.9 \%$ in $2003-2004$ and then decreased to $9.4 \%$ in 2013-2014 (Ogden et al., 2016). Childhood obesity tracks into adulthood (Nader et al., 2006) and increases the risk of hypertension, heart disease, stroke, diabetes, and some forms of cancer, which are all among leading causes of death in adults in the U.S. (Daniels, 2009). Based on the ecological systems model, the development of childhood overweight is the interaction of the child individual behaviors (dietary, physical, and sedentary) influenced by the family and school environment, embedded in the community and society as larger social contexts (Davison \& Birch, 2001). The child care environment plays an important role in the modeling of nutritional and physical activity behaviors that can impact on young children's weight status as it is likely to track throughout the rest of the life course (Cantallops, Ponseti, Vidal, Borràs, \& Palou, 2012).

More than three-fourth of U.S. children under the age of five eat at least three meals a day and engage in physical activity in child care centers (CCC) (Laughlin, 2013).

Previous studies report children in CCC are not getting the necessary daily nutritional and physical activity requirements, placing them at increased risk of overweight (Alberdi et al., 2016; Erinosho, Hales, Vaughn, Mazzucca, \& Ward, 2016). While the implementation of child care policies may contribute to better nutritional and physical activity practices for young children, previous studies indicate some states are lacking 
nutrition and physical activity policies that are consistent with national recommendations (Buscemi, Kanwischer, Becker, Ward, \& Fitzgibbon, 2015; Duffey, Slining, \& Benjamin Neelon, 2014). The implementation of policies and programs at the local and state level may also help to improve the racial, ethnic, and socioeconomic disparities in the prevalence of obesity in early childhood. Low-income groups, Hispanics, and NonHispanic Blacks are disproportionately affected by obesity and its related comorbidities (Ogden, Lamb, Carroll, \& Flegal, 2010).

Socioeconomic status plays an important role as an indicator of children's health and its effects are likely to extend to the school environment. School-level economic disadvantage has been associated with higher rates of obesity in school-aged children (Springer et al., 2015), yet its role has not been explored in the preschool population. There have been reports of socioeconomic gradients on children's diet according to the socioeconomic indicator used, further suggesting indicator specific pathways of influence on children’s dietary intake (Zarnowiecki, Ball, Parletta, \& Dollman, 2014). The child care center location may then serve as a socioeconomic indicator of household socioeconomic position (SEP), especially when parents report child care proximity to home, cost, quality of the center, and the parents' cultural preference as reasons for selection of their child's child care center (Lindsay, Salkeld, Greaney, \& Sands, 2015). It may also serve as an alternative socioeconomic indicator likely to influence on children's diet and physical activity.

In Miami-Dade County (MDC), a Hispanic minority-majority metropolitan area, 75\% of the children population under five-years of age are in some form of childcare (The 
Children’s Trust, 2015). National standards (Caring for Our Children. National Health and Safety Performance Standards; Guidelines for Early Care and Education Programs, $3^{r d}$ Edition (CFOC3) (American Academy of Pediatrics, American Public Health Association, National Resource Center for Health and Safety in Child Care and Early Education., 2011) released in 2011 lead to legislative changes in screen time, physical activity, and nutrition child care policies under the Florida Administrative Code Rule 65C-22.005. These changes required CCC that provide meals to follow the U.S. Department of Agriculture (USDA) MyPlate, June 2011 guidelines. Children $\geq 2$ yearsold were to be served low/fat-free milk and increase their consumption of whole fruits and vegetables during meals and snacks. Based on the USDA MyPlate program, the composition of breakfast would include three different food groups, lunch and dinner four different food groups, and snacks at least two different food groups. Center participants of the USDA Food Program were to provide nutritious meals and snacks in accordance with the Department of Health and the USDA requirements. Centers that did not provide meals were required to work with the parent/guardian to provide nutritional foods for the child. Centers were also required to adhere to a maximum of two-hour screen time limit per day for children $>2$ years-old. Quiet and active play indoors and outdoors were to be incorporated in the centers' routines (Florida Department of Children and Families, 2013).

Since the introduction of these policies, to our knowledge, there are no published studies found that assessed the current state of CCCs' practices and their adherence to these legislative rules. An adequate understanding of the centers' adherence to these regulations and their respective differences and barriers according to socioeconomic 
position of the center can better inform into the development and implementation of targeted initiatives or interventions to support those most affected by the increasing prevalence of overweight in the early childhood population. Guided by the ecological model (Davison \& Birch, 2001), the aims of this study were to examine: (1) the current state of CCC's adherence to nutrition, physical activity, and screen time legislative regulations; and (2) the differences in CCC's adherence to nutrition, physical activity, and screen time regulations by center SEP (low, middle, high) in Miami-Dade County, and (3) observe the differences in total active play, outdoor play, and screen time by SEP.

\section{Methods}

\section{$\underline{\text { Participants }}$}

Child care centers were identified by zip code from a local child care center database website that represented approximately 1200 centers in Miami-Dade County. To have a representative sample of child care centers in Miami-Dade County, we stratified the centers based on their zip code location into municipalities, then into low, middle, high-socioeconomic position (SEP) using the average household income for zip code from the U.S. Census data (U.S. Census Bureau, 2014). The centers were then randomly selected using probability proportional to number of centers by municipalities. Nineteen centers declined or did not respond to the invitation to participate and were replaced by centers from its own stratum. A total of 34 centers were selected who agreed to participate in the study; 15 centers were selected in the low-SEP group, 11 in the middleSEP, with oversampling of eight centers in the high-SEP group. Center directors interested in participating signed an informed consent to participate in the study. The study was approved by the Institutional Review Board. 


\section{$\underline{\text { Measures }}$}

We measured the centers' adherence to nutrition, physical activity, and screen time regulations using selected items from the Environmental and Physical Activity Environmental Observation (EPAO) instrument (Ball, Benjamin, \& Ward, 2007). A trained observer collected information on these selected items during a one-day center observation using the EPAO. Details of the observation process using the EPAO are described elsewhere (Ward et al., 2008). We measured the centers' adherence to low fat / fat free milk served to children older than two via observation of the frequency and type of milk served during meals and snacks (whole, 2\%, 1\% skim, whole-flavored, rice, soy, Lactaid, lower fat - flavored). The centers' adherence to whole fruits and vegetables was then measured via observation of their frequency served during meals and snacks. We measured centers’ adherence to quiet and active play indoors and outdoors through observation on the number of occasions and duration in minutes of total active play time (indoors, outdoors, structured, and unstructured). Center adherence to the two-hour screen time limit was measured by observation of the total number of minutes the children watched TV during the day of observation.

\section{$\underline{\text { Analysis }}$}

Means, standard deviations, and frequencies were calculated to describe the centers’ characteristics and adherence to nutritional, physical activity, and screen time legislative rules. The Statistical Package for the Social Sciences (SPSS version 23.0, 2015, SPSS Inc., Chicago, IL) was used for all analyses. $P$-values $<0.05$ were considered statistically significant. To examine the centers' adherence to local policies, we recoded the whole fruit and vegetable frequency variables to two or more times per day these were served at 
the centers. We also observed centers' adherence to screen time if the children watched two hours or less TV time during the day of observation. We ran ANOVA analyses of total minutes of active play and outdoor play per day by SEP.

\section{Results}

\section{Center characteristics}

A total of 34 centers participated in the study. Table 1 describes the centers' characteristics. All low- and middle-SEP $(\mathrm{n}=26)$ centers served breakfast, lunch, and afternoon snack. Twenty-five (73.5\%) of these centers were participants of the Child and Adult Care Food Program (CACFP). This represented 96\% of low- and middle-SEP centers. High-SEP centers $(n=8)$ were non-CACFP eligible and varied in food serving practices. Six (75\%) of these centers served snacks and children brought lunch sacks from home. Water was the beverage served by the staff during snacks in centers where lunch sacks were brought from home. The two (25\%) remaining high-SEP centers served meals and afternoon snacks. In high-SEP centers, children had a later arrival and earlier departure time, resulting in children not having afternoon naps after lunch and spending less than eight hours a day in the CCC. On the contrary, children in low and middle-SEP centers had earlier arrival and later departure times, resulting in their spending up to 12 hours a day at the center. Children in these centers had a scheduled nap time.

\section{Center adherence to state childcare regulations}

Table 2 describes the centers' adherence to nutrition, physical activity, and screen time regulations. Almost $80 \%$ of all centers followed the serving of low-fat/fat-free milk for children older than 2 years-old. Seventy-six percent of the centers observed the serving of whole fruits during meals and snacks. Only $34.5 \%$ of all centers served 
vegetables during meals and snacks. In the physical activity domain, $94 \%$ of the centers adhered to quiet and active play which were incorporated into their daily routines. All centers observed the two-hour screen-time limit for children older than 2 years-old.

\section{Center adherence to state child care regulation by SEP}

Results of centers' adherence to nutrition, physical activity, and screen-time regulations are presented in table 2. Low-SEP centers had 100\% adherence in the serving of low-fat/ fat-free milk to children older than 2 years-old, followed by middle-SEP centers (91\%). Middle-SEP centers had higher adherence to the serving of fruits during both meals and snacks over the two other SEP groups (82\%). Low-SEP centers had higher adherence in serving vegetables during meals and snacks when compared to the other SEP centers (46.7\%). Vegetable serving during both meals and snacks was absent in high-SEP centers. High-SEP centers that served meals and snacks had vegetables served only during the main lunch meal $(n=2)$.

In the physical activity domain, quiet and active play indoors and outdoors were observed in all high-SEP centers, followed by low-SEP (93\%) and middle-SEP (91\%) centers. No significant differences were noted in total minutes of active play or outdoor play by SEP. The centers' active play time averaged 79.4 minutes $(S D=33.1$, range 15133 minutes), and 26\% of them ( $n=9)$ engaged in active play between 90-120 minutes during the observation. The centers averaged one hour in outdoor play regardless of SEP. High-SEP centers had no TV or screen time exposure during the observation. Low-SEP centers had higher TV duration averaging at 29.7 minutes $(S D=31.6)$, followed by middle-SEP centers (10 minutes). 


\section{Discussion}

In our study, we aimed to examine child care centers’ adherence to current nutrition, physical activity, and screen time regulations in Miami-Dade County. Results here showed that not all centers are meeting current nutrition requirements, especially in the serving of low-fat free milk, whole fruits, and vegetables. Low- and middle-SEP centers that served meals, especially CACFP participants, had higher adherence to serving low-fat/ fat free milk, fruits, and vegetables over high-SEP centers. Overall, centers had a better adherence to serving of fruits when compared to the serving of vegetables during meals and snacks. These findings are consistent with previous reports of young children not consuming enough fruits and vegetables and failing to meet the national food group requirements (Copeland, Benjamin Neelon, Howald, \& Wosje, 2013).

The low adherence to vegetable servings during both meals and snacks is concerning, especially when it has been associated with increased adiposity later in life (Fletcher, Wright, Jones, Parkinson, \& Adamson, 2016). These findings warrant further exploration of the centers' barriers to vegetable serving at the center, child, or householdlevel. Individual factors such as food neophobia, exposure to number of vegetables, and early fruit exposure during the toddler period have been reported to track in older children's consumption of vegetables and fruits (Fletcher, Wright, Jones, Parkinson, \& Adamson, 2016). Household factors such as food insecurity, parental consumption, breastfeeding, early consumption of fruits and vegetables, consumption of unhealthy foods, family meal times, and ethnicity have been associated with child consumption of fruits and vegetables (Asfour et al., 2015; Cooke et al., 2004). Center factors such as food 
availability, variety, repeated exposure, as well as the food structure, food modeling, and food socialization practices may influence children's fruit and vegetable consumption at the center level (Nicklas et al., 2001)(Erinosho, Dixon, Young, Brotman, \& Hayman, 2011).

We must also highlight the lack of vegetables served in high-SEP centers and low serving of vegetables in middle-SEP centers as another important finding of this study. Only $12.5 \%$ of centers in the high-SEP group served whole fruits during the observation. Our findings suggest a disparity towards middle and high-SEP groups not meeting national recommendations for daily dietary consumption of fruits and vegetables. Our findings align with previous studies that report children in centers recipients of the CACFP benefit from better nutrition when compared to non-CACFP centers (Ritchie et al., 2012). The centers' participation in the CACFP program moderately increases the consumption of milk and vegetables over non-participant centers and may reduce the prevalence of overweight and underweight (Korenman, Abner, Kaestner, \& Gordon, 2013). Other factors to consider include the modeling of early childhood teachers of healthy dietary behaviors (Erinosho, Hales, McWilliams, Emunah, \& Ward, 2012), which may be limited especially in centers were meals and snacks are not served. Centers with accessibility to nutrition performance standards and increased nutrition-training opportunities fare better in childcare feeding practices (Dev \& McBride, 2013). There is success in modeling of healthy nutrition behaviors leading to healthier food practices in preschool children and parents with childcare staff training on role modeling of these behaviors (Natale, Lopez-Mitnik, Uhlhorn, Asfour, \& Messiah, 2014). 
While low-SEP and middle-SEP centers served more fruits and vegetables over high-SEP centers, not all centers were adhering to the rule of serving these during both meals and snacks. Our findings also correlate with previous reports that center participants generally comply with CACFP recommendations, but they may fail in meeting Institute of Medicine recommendations for saturated fats, proteins, fiber, and sodium (Schwartz et al., 2015). We must also highlight that high-SEP centers where only snacks were served were limited in their adherence to the serving of low-fat/ fat-free milk, fruits, and vegetables. These centers relied on parents to support the nutritional needs of their children as indicated in the legislative rule that centers that do not provide meals were required to work with the parent/guardian to provide nutritional foods for the child. Limited studies of lunch sacks in preschoolers report these to be lacking in quality, especially in the inclusion of vegetables, proteins, and grains (Romo-Palafox et al., 2015). Studies further report concerns with perishable items not maintaining safe temperature zones despite the use of multiple ice packs (Almansour et al., 2011). These findings have implications into the need for studies to explore any possible barriers centers may face in the low serving of vegetables during both meals and snacks. Additional studies are also needed to explore barriers to serving of milk, fruits, and vegetables in high-SEP centers that served meals and snacks and centers where only snacks are served and children bring lunch sacks from home. Parental cultural, ethnic factors, and dietary and religious preferences in types of lunches served is another important consideration, and these may extend to centers that may observe these practices as well. 
All centers in this study had incorporated active play indoor and outdoor into their routines. However, they may not be meeting the national recommendations of two to three outdoor occasions of 60-90 minutes per day and 90-120 minutes of moderate-tovigorous activity per day (American Academy of Pediatrics, American Public Health Association, National Resource Center for Health and Safety in Child Care and Early Education., 2011). Factors such as the presence of physical activity staff training and policies at the center need to be explored. Studies report settings where physical activity policies are absent, there is low child participation rates in activity programs (Gerritsen, Morton, \& Wall, 2016). Previous studies report centers may be lacking in opportunities for structured, outdoor activities (Benjamin, Haines, Ball, \& Ward, 2008). Children are also more active and less sedentary during unstructured, outdoor, and child-led or initiated indoor or outdoor active play opportunities (Tandon, Saelens, \& Christakis, 2015). These findings further suggest the need for more prescriptive policies that may align centers' practices with national recommendations for active play or physical activity. Another positive finding of this study was the centers' adherence to screen-time regulation. However, the centers' efforts need to be continued as national standards advocate for 30 minutes of screen time once a week (American Public Health Association, National Resource Center for Health and Safety in Child Care and Early Education., 2011).

Strengths of the study include the use of the EPAO instrument as an objective observation measure of the centers' adherence to nutrition, physical activity, and screen time regulations. Limitations of the study include the cross-sectional design of this study and the observation of the centers' adherence limited to a one-day observation. It was not 
possible to determine whether the implementation of the legislative rule may have contributed to possible changes in practices at the centers. Another limitation to discuss includes the variability in child care center nutrition practices, especially the mode of meals served in high-SEP centers. Other limitation of the study was the lack of inclusion of individual determinants which may be contributing factors into children's dietary preferences. The findings from our study have implications into the identification of barriers and possibly the implementation of programs to support CCCs, especially those were meals are not served. Further studies are warranted to explore the role of the child care environment as a socioeconomic indicator of children's health. Middle and high-SEP centers may also benefit from the resources and technical assistance to support healthier diets in young children available to centers supported by the USDA food program. Local, state, and federal policies may also help maximize the child care environment's effect in young children's nutrition, physical activity, and screen time behaviors (Erinosho, Hales, Vaughn, Mazzucca, \& Ward, 2016). More prescriptive nutrition and physical activity policies are likely to have major impact on child care practices and may help narrow the developmental gaps between high and low-SEP children (Buscemi, et al., 2015;

Gialamas, Mittinty, Sawyer, Zubrick, \& Lynch, 2015).

\section{Conclusions}

This is the first study to examine child care centers' adherence to legislative changes in nutritional, physical activity, and screen time practices in Miami-Dade County. Low- and middle-SEP centers fared better in their adherence to nutrition regulations, especially the serving of low/ fat-free milk and whole fruits, when compared to high-SEP centers. Serving of vegetables was lower compared to serving of fruits in 
low- and middle-SEP centers. High-SEP centers were lacking the most in serving of vegetables during meals and snacks. All low- and middle-SEP centers served meals and snacks, and almost all of them were CACFP participants. Our findings have implications for continued work in the in the practice and policy arena to better align child care center nutrition, physical activity, and screen-time practices with national standards.

\section{References}

Almansour, F. D., Sweitzer, S. J., Magness, A. A., Calloway, E. E., McAllaster, M. R., Roberts-Gray, C. R., . . . Briley, M. E. (2011). Temperature of foods sent by parents of preschool-aged children. Pediatrics, 128(3), 519-523. doi:10.1542/peds.2010-2885

Alberdi, G., McNamara, A. E., Lindsay, K. L., Scully, H. A., Horan, M. H., Gibney, E. R., \& McAuliffe, F. M. (2016). The association between childcare and risk of childhood overweight and obesity in children aged 5 years and under: a systematic review. Eur J Pediatr, 175(10), 1277-1294. doi:10.1007/s00431-0162768-9

American Academy of Pediatrics, American Public Health Association, \& Education., National Resource Center for Health and Safety in Child Care and Early Education. (2011). Caring for our Children: National health and safety performance standards; Guidelines for early care and education programs. $3^{\text {rd }}$ edition. Elk Grove Village, IL: American Academy of Pediatrics; Washington, DC: American Public http://cfoc.nrckids.org/

Asfour, L., Natale, R., Uhlhorn, S., Arheart, K. L., Haney, K., \& Messiah, S. E. (2015). Ethnicity, Household Food Security, and Nutrition and Activity Patterns in Families With Preschool Children. J Nutr Educ Behav, 47(6), 498-505 e491. doi:10.1016/j.jneb.2015. 07.003

Ball, S. C., Benjamin, S. E., \& Ward, D. S. (2007). Development and reliability of an observation method to assess food intake of young children in child care. $J$ Am Diet Assoc, 107(4), 656-661. doi:10.1016/j.jada.2007.01.003

Buscemi, J., Kanwischer, K., Becker, A. B., Ward, D. S., \& Fitzgibbon, M. L. (2015). Society of Behavioral Medicine position statement: early care and education (ECE) policies can impact obesity prevention among preschool-aged children. Transl Behav Med, 5(1), 122-125. doi:10.1007/s13142-014-0297-5 
Cantallops, J., Ponseti, F. J., Vidal, J., Borràs, P. A., \& Palou, P. (2012). Adolescence, physical inactivity and overweight: analysis based on socio-personal variables of the parents and the type of sport practiced by the children. Retos. Nuevas tendencias en Educación Física. Deporte y Recreación, 21.

Cooke, L. J., Wardle, J., Gibson, E. L., Sapochnik, M., Sheiham, A., \& Lawson, M. (2004). Demographic, familial and trait predictors of fruit and vegetable consumption by pre-school children. Public Health Nutr, 7(2), 295-302. doi:10.1079/phn2003527

Copeland, K. A., Benjamin Neelon, S. E., Howald, A. E., \& Wosje, K. S. (2013). Nutritional quality of meals compared to snacks in child care. Child Obes, 9(3), 223-232. doi:10.1089/chi.2012.0138

Daniels, S. R. (2009). Complications of obesity in children and adolescents. Int J Obes (Lond), 33 Suppl 1, S60-65. doi:10.1038/ijo.2009.20

Davison, K. K., \& Birch, L. L. (2001). Childhood overweight: a contextual model and recommendations for future research. Obes Rev, 2(3), 159-171.

Dev, D. A., \& McBride, B. A. (2013). Academy of Nutrition and Dietetics benchmarks for nutrition in child care 2011: are child-care providers across contexts meeting recommendations? J Acad Nutr Diet, 113(10), 1346-1353. doi:10.1016/j.jand. 2013.05.023

Duffey, K. J., Slining, M. M., \& Benjamin Neelon, S. E. (2014). States lack physical activity policies in child care that are consistent with national recommendations. Child Obes, 10(6), 491-500. doi:10.1089/chi.2014.0096

Erinosho, T., Hales, D., Vaughn, A., Mazzucca, S., \& Ward, D. S. (2016). Impact of Policies on Physical Activity and Screen Time Practices in 50 Child-Care Centers in North Carolina. J Phys Act Health, 13(1), 59-66. doi:10.1123/jpah.2014-0467

Erinosho, T., Dixon, L. B., Young, C., Brotman, L. M., \& Hayman, L. L. (2011). Nutrition practices and children's dietary intakes at 40 child-care centers in New York City. J Am Diet Assoc, 111(9), 1391-1397. doi:10.1016/j.jada.2011.06.001

Erinosho, T. O., Hales, D. P., McWilliams, C. P., Emunah, J., \& Ward, D. S. (2012). Nutrition policies at child-care centers and impact on role modeling of healthy eating behaviors of caregivers. J Acad Nutr Diet, 112(1), 119-124. doi:10.1016/j.jada.2011.08.048

Fletcher, S., Wright, C., Jones, A., Parkinson, K., \& Adamson, A. (2016). Tracking of toddler fruit and vegetable preferences to intake and adiposity later in childhood. Matern Child Nutr. doi:10.1111/mcn.12290 
Florida Department of Children and Families. (2013). Florida Administrative Code and Florida Administrative Register. Final Section 65c-22.005. Food and Nutrition. Retrieved from https://www.flrules.org/Gateway/reference.asp?No=Ref-03036.

Gerritsen, S., Morton, S. M., \& Wall, C. R. (2016). Physical activity and screen use policy and practices in childcare: results from a survey of early childhood education services in New Zealand. Aust N Z J Public Health, 40(4), 319-325. doi:10.1111/1753-6405.12529

Gialamas, A., Mittinty, M. N., Sawyer, M. G., Zubrick, S. R., \& Lynch, J. (2015). Social inequalities in childcare quality and their effects on children's development at school entry: findings from the Longitudinal Study of Australian Children. $J$ Epidemiol Community Health, 69(9), 841-848. doi:10.1136/jech-2014-205031.

Institute of Medicine. (2011). Child and Adult Care Food Program: Aligning dietary guidance for all. Washington, D.C.: The National Academies Press Retrieved from http://www.nap.edu/read/12959/chapter/1.

Korenman, S., Abner, K. S., Kaestner, R., \& Gordon, R. A. (2013). The Child and Adult Care Food Program and the Nutrition of Preschoolers. Early Child Res Q, 28(2), 325-336. doi:10.1016/j.ecresq.2012.07.007

Laughlin, L. (2013). Who's minding the kids? Child Care Arrangements: Spring 2011. Washington, DC: Current Populations Report.

Lindsay, A. C., Salkeld, J. A., Greaney, M. L., \& Sands, F. D. (2015). Latino family childcare providers' beliefs, attitudes, and practices related to promotion of healthy behaviors among preschool children: a qualitative study. J Obes, 2015, 409742. doi:10.1155/2015/409742

Nader, P. R., O'Brien, M., Houts, R., Bradley, R., Belsky, J., Crosnoe, R., . . Susman, E. J. (2006). Identifying risk for obesity in early childhood. Pediatrics, 118(3), e594601. doi:10.1542/peds.2005-2801

Natale, R. A., Lopez-Mitnik, G., Uhlhorn, S. B., Asfour, L., \& Messiah, S. E. (2014). Effect of a child care center-based obesity prevention program on body mass index and nutrition practices among preschool-aged children. Health Promot Pract, 15(5), 695-705. doi:10.1177/1524839914523429

Nicklas, T. A., Baranowski, T., Baranowski, J. C., Cullen, K., Rittenberry, L., \& Olvera, N. (2001). Family and child-care provider influences on preschool children's fruit, juice, and vegetable consumption. Nutr Rev, 59(7), 224-235.

Ogden, C. L., Carroll, M. D., Lawman, H. G., Fryar, C. D., Kruszon-Moran, D., Kit, B. K., \& Flegal, K. M. (2016). Trends in Obesity Prevalence Among Children and 
Adolescents in the United States, 1988-1994 Through 2013-2014. JAMA, 315(21), 2292-2299. doi:10.1001/jama.2016.6361

Ogden, C. L., Lamb, M. M., Carroll, M. D., \& Flegal, K. M. (2010). Obesity and socioeconomic status in adults: United States, 2005-2008. NCHS Data Brief(50), $1-8$.

Ritchie, L. D., Boyle, M., Chandran, K., Spector, P., Whaley, S. E., James, P., . . . Crawford, P. (2012). Participation in the child and adult care food program is associated with more nutritious foods and beverages in child care. Child Obes, 8(3), 224-229. doi:10.1089/chi.2011.0061

Romo-Palafox, M. J., Ranjit, N., Sweitzer, S. J., Roberts-Gray, C., Hoelscher, D. M., Byrd-Williams, C. E., \& Briley, M. E. (2015). Dietary Quality of Preschoolers' Sack Lunches as Measured by the Healthy Eating Index. J Acad Nutr Diet, 115(11), 1779-1788. doi:10.1016/j.jand.2015.05.017

Schwartz, M. B., Henderson, K. E., Grode, G., Hyary, M., Kenney, E. L., O'Connell, M., \& Middleton, A. E. (2015). Comparing Current Practice to Recommendations for the Child and Adult Care Food Program. Child Obes, 11(5), 491-498. doi:10.1089/chi.2015.0041

Springer, A. E., Li, L., Ranjit, N., Delk, J., Mehta, K., \& Kelder, S. H. (2015). Schoollevel economic disadvantage and obesity in middle school children in central Texas, USA: a cross-sectional study. Int J Behav Nutr Phys Act, 12 Suppl 1, S8. doi:10.1186/1479-5868-12-s1-s8

Tandon, P. S., Saelens, B. E., \& Christakis, D. A. (2015). Active play opportunities at child care. Pediatrics, 135(6), e1425-1431. doi:10.1542/peds.2014-2750

The Children’s Trust. (2015). Annual Report 2015. Miami, Florida Retrieved from https://www.thechildrenstrust.org/publications/annual-reports.

Ward, D., Hales, D., Haverly, K., Marks, J., Benjamin, S., Ball, S., \& Trost, S. (2008). An instrument to assess the obesogenic environment of child care centers. Am J Health Behav, 32(4), 380-386. doi:10.5555/ajhb.2008.32.4.380

Zarnowiecki, D., Ball, K., Parletta, N., \& Dollman, J. (2014). Describing socioeconomic gradients in children's diets - does the socioeconomic indicator used matter? Int $J$ Behav Nutr Phys Act, 11(1), 44. doi:10.1186/1479-5868-11-44 
Tables and figures

TABLE 1

Child Care Center Characteristics $(n=34)$

\begin{tabular}{lc} 
Center Characteristics & All Centers (n, \%) \\
\hline Type of Center & $24(70.6 \%)$ \\
Private & $4(11.8 \%)$ \\
Head Start & $3(8.8 \%)$ \\
Hospital-based & $3(8.8 \%)$ \\
Religious-based & \\
Child Care Adult Food Program (CACFP) Participant & $25(73.5 \%)$ \\
Centers that provide meals and snacks & $27(81.8 \%)$ \\
Centers that provide snacks only & $6(18.2 \%)$ \\
Centers that practices lunch sacks from home & $6(18.2 \%)$ \\
\hline
\end{tabular}

${ }^{a}$ Demographic Information reported by facility directors 
TABLE 2

Frequency (\%) of centers' adherence ${ }^{\mathrm{a}}$ to nutrition, physical activity and screen time regulations ${ }^{b}$

\begin{tabular}{|c|c|c|c|c|}
\hline Domains & $\begin{array}{l}\text { Total } \\
(n=34)\end{array}$ & $\begin{array}{l}\text { Low-SEP } \\
(n=15)\end{array}$ & $\begin{array}{l}\text { Middle-SEP } \\
\quad(n=11)\end{array}$ & $\begin{array}{l}\text { High-SEP } \\
\quad(n=8)\end{array}$ \\
\hline \multicolumn{5}{|l|}{ Nutrition } \\
\hline $\begin{array}{l}\text { Low/fat free milk served } \\
\text { to children } \geq 2 \text { years-old }\end{array}$ & 79.4 & 100 & 90.9 & 25.0 \\
\hline $\begin{array}{l}\text { Whole fruits served } \\
\text { during meals and snacks } \\
\text { ( } \geq 2 \text { times per day) }\end{array}$ & 75.9 & 80 & 81.8 & 12.5 \\
\hline $\begin{array}{l}\text { Vegetables consumed } \\
\text { during meals and snacks } \\
\text { ( } \geq 2 \text { times per day) }\end{array}$ & 34.5 & 46.7 & 25.1 & -- \\
\hline Physical Activity & & & & \\
\hline $\begin{array}{l}\text { Quiet and active play } \\
\text { indoor /outdoor in daily } \\
\text { routines }\end{array}$ & 94.1 & 93.3 & 90.9 & 100 \\
\hline $\begin{array}{l}\text { Total minutes active } \\
\text { play }(x, S D)\end{array}$ & $79.4(33.1)$ & $81.6(24.0)$ & $76.2(35.4)$ & $80.0(45.7)$ \\
\hline $\begin{array}{l}\text { Total minutes outdoor } \\
\text { play/day } \\
(x, S D) \\
\text { Screen Time }\end{array}$ & $62.8(35.9)$ & $61.3(24.9)$ & $62.6(32.9)$ & $62.1(30.0)$ \\
\hline $\begin{array}{l}\text { Two-hour screen time } \\
\text { limit for children }>2 \\
\text { years-old }\end{array}$ & 100 & 100 & 100 & 100 \\
\hline Total minutes TV time $(x)$ & $17^{\mathrm{c}}$ & 29.7(31.6) & 10.0 & -- \\
\hline
\end{tabular}

${ }^{a}$ Based on observation using EPAO measure. ${ }^{\mathrm{b}}$ According to Florida childcare

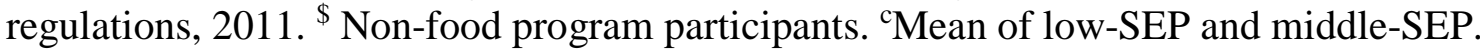




\title{
MANUSCRIPT 3
}

\section{Exploring Early Feeding, Dietary, Sedentary, Ethnic and Socioeconomic Determinants of Unhealthy Weight in Preschoolers}

\begin{abstract}
BACKGROUND: There are persisting socioeconomic and ethnic disparities in obesity in preschoolers in the United States. AIM: We sought to examine the prevalence of overweight and obesity and early life, dietary, and screen-time behaviors associated with overweight status, ethnicity, and socioeconomic position in preschoolers. METHODS: Cross-sectional study of 3 to 5 -year-old children $(n=366)$ from 34 child care centers in Miami, Florida. Socioeconomic position (SEP) determined by child care center location. Caregivers completed questionnaire on socioeconomic, early life, dietary, and screentime factors. We measured children’s heights and weights. Chi-square and logistic regression analyses were used to examine the association between overweight (BMI $\geq$ $85^{\text {th }}$ percentile for age and sex) and determinants adjusting for age, gender, race, and SEP. RESULTS: The prevalence of overweight was $29.8 \%$ in the sample. The middleSEP group had the highest prevalence of overweight (35.3\%) when compared to low and high-SEP groups. Being Hispanic was associated with a nearly three-fold risk of being overweight/ obese (AOR: 2.91, 95\% CI 1.36, 6.21). Lack of daily consumption of fruits increased the risk of overweight in Hispanic children. Middle-SEP children reported lowest consumption of fruits and vegetables. There were significant differences in breastfeeding practices by ethnicity and SEP. CONCLUSIONS: Middle-SEP group had lowest consumption of fruits and vegetables and highest prevalence of overweight and obesity. Hispanics had highest prevalence of overweight and obesity. Increasing awareness in early feeding practices and nutritional practices in the consumption of fruits
\end{abstract}


and vegetables in children in child care could improve the weight status of young children, especially in Hispanics and middle-SEP children.

KEYWORDS: overweight, preschool, socioeconomic, ethnicity, fruits, early-life, screen-time 


\section{Introduction}

The prevalence of unhealthy weight (e.g. overweight, obesity) in preschool-age children remains a public health problem in the United States. Obesity rates in two-tofive-year-old children increased from 7.2\% in 1988-1994 to 9.4\% in 2013-2014 [1]. Childhood obesity is caused by the energy imbalance from increased intake of caloriedense, low-nutrient foods and beverages, limited physical activity, and increased sedentary behaviors [2-4]. Consequently, overweight children face a four-fold risk of adult obesity $[8,9]$ and a lifetime risk in the development of cardiovascular disease, metabolic syndrome, psychological problems, and premature death [10, 11]. Early feeding practices, including the short duration of breastfeeding and early introduction to solid foods may play a role in a young child's food preferences and increase the risk of childhood obesity [5, 6]. For the nearly eleven million children under the age of five enrolled in child care, both the household and child care environments play an important role in the modeling of these lifestyle behaviors [7].

Socioeconomic disadvantage increases the risk for and rate at which children become obese [12-16][15]. However, the specific mechanisms underlying the socioeconomic differences in obesity risk factors within the household environment remains unclear [17-20]. There has been the lack of consensus in the use of socioeconomic indicators, resulting in socioeconomic gradients in determinants such as children's diet corresponding to the socioeconomic indicator used [21]. Recent studies report that child's school location as a measure of economic disadvantage is likely to influence the prevalence of obesity in older children [22]. As such, the child care center location may serve as an indicator of household socioeconomic status in families of young children, 
especially when parents report child care center cost, proximity to home, quality, and hours of operation as reasons for center selection [23, 24].

There are racial and ethnic disparities in the prevalence of childhood obesity, which may attenuate the socioeconomic differences in selected obesity factors for lowincome groups [25]. Some studies report an increasing body mass index (BMI) trajectory in Hispanics compared to other ethnic groups [26, 27]. Hispanics represent $17.6 \%$ of the U.S. population and have become the largest ethnic minority in the United States [28], yet they continue to be underrepresented in the studies [20]. In Miami-Dade County (MDC), an ethnically diverse metropolitan area in the state of Florida, Hispanics represent $66.8 \%$ of its population [28]. A previous study reported $27.9 \%$ of teens and 63.6\% of adults living in MDC were overweight or obese [29]. To our knowledge there are no published studies that have analyzed racial, ethnic, and socioeconomic determinants of overweight/obesity in preschoolers using child care center location as an indicator of socioeconomic position (SEP). Guided by the maternal-child life course approach [5] the aims of this study were to examine: (1) early feeding, current dietary,

and screen-time behaviors associated with overweight/obesity in preschoolers; and (2) the association between these determinants, race/ethnicity, and socioeconomic position in preschoolers from child care centers located in socioeconomically diverse MDC municipalities.

\section{Methods}

\section{Study Design}

We conducted a cross-sectional survey of 366 parents/caregivers of three-to-fiveyear-old children from 34 child care centers located in various MDC municipalities. 
MDC has a population of 2,693,117, where $66.8 \%$ are Hispanic and $72.8 \%$ of households report a language other than English being the dominant language [28]. The centers were identified by zip code from a local child care center database website of approximately 1,200 child care centers. We stratified the centers based on zip code into low, middle, and high-SEP strata using the average household income for zip code from the U.S. Census data [30]. The centers were randomly selected using probability proportional to size (number of centers by municipalities). A total of 15 centers in the low-SEP, 11 in the middle-SEP, and eight in the high-SEP strata were selected. The 3-,4-,5- year-old classrooms were selected from each of these centers. Nineteen centers declined or did not respond to the invitation to participate and were replaced by centers from its own stratum. This resulted in a total of 34 centers who agreed to participate in the study.

Based on effect size (OR=1.39, 1.19, 1.61) from a previous study [31], the sample size that was calculated with a power of $80 \%$, and $\alpha=0.05$ resulted in 359 participants (G*Power for Windows version 3.1.5, 2012). Accounting for 35\% non-response rate, we targeted a total sample of 486 parent-child participants from the child care centers. Our final sample included 366 parents/ caregiver-child dyads. The study was approved by the Institutional Review Board of the university. Parents who agreed to participate signed an informed consent form to have their child's height and weight measured at their child care center. Parents completed a paper-based survey with questions on sociodemographic, early feeding, and selected dietary and sedentary practices written at sixth-grade level in English and Spanish. Validated items were adapted from the Healthy Kids Checklist utilized in a previous study [32, 33]. 


\section{$\underline{\text { Anthropometry and demographic measurements }}$}

Child height and weight were measured using a Seca portable stadiometer and Taylor 7403 digital scale. Age and sex-adjusted Body Mass Index (BMI) z- scores were calculated using the Center for Disease Control and Prevention (CDC) SAS macro [34]. Children were categorized as being overweight and obese $\left(\geq 85^{\text {th }}\right.$ BMI percentile adjusted for age and sex) [34]. We measured child socioeconomic status using the child care center location as an indicator of household SEP. We asked caregivers whether they received free or reduced childcare subsidies. MDC low-income residents are eligible for free or reduced child care as part of the school child readiness program [35]. We collected caregivers' information about their country of birth, age, relationship to child, and level of education. We categorized the country of birth as USA or other, and the education variable into high school or less, some college, and associate degree or higher. Other measures included the child gender, age, country of birth, and race/ethnicity. Child race/ethnicity was categorized as Hispanic, non-Hispanic Black, non-Hispanic White, and other based on U.S. Census definition [30].

\section{Early life factors, nutritional, and screen-time behaviors}

Caregivers were asked about their child's duration of breastfeeding, formulafeeding, and initiation of solid foods in months. We dichotomized the bottle-feeding, breastfeeding, and solid food variables using six-month duration as the reference. Caregivers were asked about the child's frequency in consuming fruits, vegetables, soda with meals, fruit juice or sport drink or punch during the day. The response categories were dichotomized into daily versus none. We dichotomized soda and fruit juice or sport drink or fruit punch variables as yes/ no based on national guidelines discouraging the 
consumption of sweetened beverages in young children [36]. Dichotomized sedentary questions included child watching TV during meals and having a television (TV) or screen-time device in the bedroom. We asked caregivers about the amount of time child spent watching TV, DVDs or videos, playing computer games, games consoles or on smart phone/tablet apps on weekdays and weekends. We dichotomized the weekend and weekday screen-time responses (none, 1-30 minutes, 31-60 minutes, 1-2 hours, 2-4 hours, and more than 4 hours) to $\leq 30$ minutes. Based on national recommendations, children over two years old should watch no more than one to two hours of high-quality programming. Children who are in child care should be exposed to only 30 minutes of total screen time per week while in child care [37].

$\underline{\text { Analysis }}$

All analyses were performed using SPSS version 23.0, 2015 (SPSS Inc, Chicago, IL). Detailed characteristics were stratified by overweight/obese status, race/ ethnicity and SEP. Chi square analysis was used to generate the associations of early feeding factors, selected dietary and sedentary behaviors, and demographic factors. Bivariate logistic regression analysis was performed to assess the association between each predictor and child overweight/obese status as the dependent variable. The Concordance Index was estimated to evaluate the discrimination performance of the logistic regression model. Predictors that were significant up to $p<0.20$ within each of the respective domains (early nutrition, dietary, sedentary, and sociodemographic) were included in the multiple regression models. We performed multiple logistic regression analyses using a backward elimination approach to determine the association between these factors and child overweight/obese status. Adjusted ORs (AOR) with 95\% CI were calculated. 


\section{Results}

\section{$\underline{\text { Participant Characteristics }}$}

Table 1 shows the children characteristics, early feeding, dietary, and sedentary household practices stratified by weight status. The children participants were U.S. born (93\%), female (53\%), mean age $3.8+0.7$ years enrolled in child care centers from various MDC municipalities. The ethnic composition of our sample was representative of the population of children living in MDC. Sixty-seven percent $(n=241)$ of the children were Hispanic, born in the U.S. (96\%). The caregivers were mothers (85\%), mean age $34.2+7.6$ years-old, U.S. born (52\%), and had an associate degree or higher (52\%). The prevalence of overweight and obesity was $29.8 \%(n=109)$. Ten percent $(n=38)$ of the children were classified as obese. The mean child BMI was $16.1 \pm 1.6 \mathrm{~kg} / \mathrm{m}^{2}$. The mean BMI percentile and BMI z-score in the overweight ones were 92.3+ 4.5 and $1.1+0.15$ respectively. The middle-SEP group had the highest prevalence of overweight and obesity (35.3\%) when compared to the other SEP groups. Hispanics had the highest prevalence of overweight and obesity (34.6\%) when compared to the other ethnic groups (non-Hispanic Whites, Blacks, and others $)(P=0.003)$.

\section{Early feeding factors}

Table 2 shows the proportion of children's early feeding practices by ethnicity and SEP. The duration of breastfeeding (65\%)and bottle-feeding (97.9\%) was short in this sample ( $<6$ months). There were significant differences in breastfeeding practices by ethnicity and SEP. Non-Hispanic Blacks (52\%), the low-SEP (64\%), and middle-SEP (68\%) groups reported the lowest breastfeeding rates $(\mathrm{p}<0.05)$. Hispanic children were breastfed for less than six months (71\%). Nearly half- of the sample $(n=155)$ were 
introduced to solid foods within the first six months of life. This practice was more prevalent in Hispanics (53\%) and within the high-SEP group (60\%). There were no significant differences in early feeding practices (breastfeeding, early introduction to solid foods) and child overweight and obese status.

Dietary consumption of fruits, vegetables, and sweetened beverages

Table 2 shows the proportion of the children's dietary and sedentary practices by ethnicity and SEP. Overall, the daily consumption of fruits (44\%) and vegetables (29\%) was low in this sample of preschoolers. Non-Hispanic Whites (41.9\%) reported the lowest daily consumption of fruits. Hispanics (23.4\%) reported the lowest daily consumption of vegetables. By SEP, the middle-SEP group reported the lowest daily consumption of fruits (35\%) and vegetables (22\%). Fruit juices and sport drinks were consumed with more frequency by the preschoolers (74\%). These differences were not statistically significant. Non-Hispanic Blacks (51\%) reported highest consumption of sodas with meals. This practices was least prevalent in the high-SEP (19\%) group $(P<$ 0.05). More than one-third of the children who reported lack of daily consumption of fruits and vegetables were overweight or obese. Only the daily consumption of fruits was significantly associated with child overweight or obese status $(P<0.05)$.

\section{Child sedentary practices}

Nearly half of the sample (44.3\%) reported having a TV or screen device in the child's bedroom. This practice was least prevalent in non-Hispanic whites (32.4\%) $(P<$ 0.05). More than one-third of the children reported screen-time use between 1-2 hours throughout the week. There were no significant differences in screen-time use by 
ethnicity or SEP. Only screen-time use on weekends was significantly associated with child overweight or obese status.

\section{Determinants of child overweight and obese status}

Table 3 shows the results of the multiple logistic regression analyses using backward stepwise elimination approach. The combination of daily fruit consumption with screen-time use on weekends was significantly associated with child overweight or obese status after adjustment for age, gender, SEP, and ethnicity. Children who failed to consume daily fruits had a two-fold risk of overweight or obesity in this sample (AOR: 2.26, 95\% CI 1.13, 4.52, $P=0.022$ ). The least significant variables (breastfeeding exposure, screen-time use during the week, daily vegetable consumption) were eliminated by the backward stepwise logistic procedure as these were not significant.

Being that Hispanics had the highest prevalence of overweight in this sample, we dichotomized the Hispanic variable and ran backward stepwise multiple logistic regression analyses. Results indicated Hispanics having a three-fold risk of being overweight/ obese (AOR: 2.91, 95\% CI 1.36, 6.21, $P=0.006)$. Hispanic children who failed to consume fruits daily were twice as likely to be overweight or obese (AOR: 2.23, 95\% CI 1.12, 4.45, $P=0.023)$. Weekend screen-time use resulted in reduced risk of overweight/ obesity in the Hispanic preschoolers (AOR: 0.34, 95\% CI 0.11, 1.08, $P=$ 0.066). The results of the model were significant $(P=.0001)$. However, the area under the curve was $68.2 \%$, thus indicating that we need to view these results with caution in the predictive use of this model. 


\section{Discussion}

This is the first study to date to examine the prevalence of overweight and obesity by socioeconomic position in a representative sample of children enrolled in child care centers in Miami-Dade County, Florida. We also studied early life feeding, selected dietary, and sedentary behaviors associated with overweight and obese status, stratified by ethnicity and SEP. The prevalence of overweight and obesity was $29.8 \%$ in this sample. The middle-SEP group had the highest prevalence of overweight and obesity (35.3\%) when compared to the low-SEP and high-SEP groups. In the context of socioeconomic status, we had expected the middle-SEP and high-SEP children in this sample to have a leaner weight status despite their enrollment in child care. Our findings contradict previous reports of an inverse association between socioeconomic status and adiposity in children $[40,58]$, especially when low-income groups have been experiencing higher prevalence rates of overweight and obesity in the U.S. [59].

These overall findings are concerning, especially when the middle-income group comprises $50 \%$ of the U.S. population [38], composed of dual- and single-working parent households requiring the use of child care services. An increasing number of studies have reported an association between early child care and increasing BMI status in young children [60]. The children in this study were enrolled in child care. Another important finding was the increased prevalence of overweight and obesity in Hispanic children. Being Hispanic was associated with a nearly three-fold increased risk of overweight and obesity in our sample. Our findings are consistent with previous reports of increasing trends in the prevalence of obesity in Hispanic preschoolers in varied geographical locations in the U.S. [43, 44, 61-63]. The healthy migrant effect or Hispanic paradox may 
not be applicable to Hispanic preschoolers born in the U.S. [45, 64]. The children in our sample were U.S. born and represent second-generation immigrants raised in an ethnically diverse metropolitan city where Hispanics represent the ethnic minority majority.

Consistent with previous reports of child care associated with unfavorable early feeding practices [65], the children in our study reported short exposure to the breastfeeding as well as early introduction to solid foods during the first six months of life. The ethnic and socioeconomic differences in these practices warrant further exploration into the barriers to breastfeeding, especially in Hispanics and non-Hispanic Blacks. Previous studies report nativity and migrant status as underlying factors that may be contributing to these ethnic differences [66]. Early introduction to solid foods before the first four months of life, early child care during infancy, and inappropriate bottle-use have been reported to increase the risk of overweight in young children [67]. These findings have implications in the implementation of local programs to support better early feeding practices for infants and children enrolled in childcare. Being that the middle and high-SEP groups reported shorter breastfeeding duration combined with early introduction to solid foods suggest that these programs and interventions should outreach to all children in the community regardless of socioeconomic status. We must also highlight the early life course approach with some of these initiatives taking place during the maternity period in the primary care setting, taking into account cultural considerations [68].

Our findings also suggest that preschool children may not be getting the necessary recommended dietary requirements to sustain a healthy weight balance in the home 
environment. While Hispanics reported the lowest daily consumption of vegetables, the lack of daily consumption of fruits increased the risk of overweight when combined with sedentary activity on weekends in this ethnic subgroup. The middle-SEP group reported overall lower consumption of fruits and vegetables when compared to the low-SEP and high-SEP group. Previous studies report racial and ethnic differences in fruit and vegetable intake based on country of nativity [69]. Factors not explored in this study include ethnicity of non-Hispanic black children, especially when it has been previosuly reported the presence of ethnic subgroups (Haitians, other Caribbeans) in Miami-Dade County. Possible barriers associated with decreased consumption of fruits and vegetables include accessibility to foods, food security [70], as well as parental modeling in the consumption of fruits and vegetables [71].

The consumption of sweetened beverages was prevalent in this sample. Sedentary practices, eating a meal while watching television (TV), having a TV in the child's bedroom, and increased screen-time especially on weekends may be contributing to the increasing weight status in these preschoolers. These findings are consistent with previous studies [54]. By SEP, the low-SEP and middle-SEP groups reported the higher sedentary practices. Having a TV in the child's bedroom was prevalent in Hispanics and non-Hispanic blacks who represented the ethnic majority in the low-SEP and middle-SEP groups. Previous studies report these practices being prevalent in low and middle-income children [54]. In the context of socioeconomic location, children living in neighborhoods with increased exposure to crime, limited greenery and walkable space, may be limited in options to engage in physical activity in a safe environment [72]. The ethnic differences observed in these sedentary practices, especially in the Hispanic and non-Hispanic Black 
group suggest that ethnicity plays an important role in the sedentary practices in the home environment. Ethnic and cultural factors should be considered in obesity prevention efforts in the childhood population. Previous studies report specific sedentary practices being more prevalent in some ethnic groups [55]. Practices such as the presence of a TV in the child's bedroom increase the risk of overweight in preschoolers [56] and has been associated with shorter sleep time at night [57]. However, it was not explored in the current study.

Our study had limitations. First, the cross-sectional design of our study does not allow for statements about causality; in this case early feeding behaviors causing early childhood unhealthy weight. The self-reporting and lack of responses to some of the questions by the caregivers limited our findings and may have contributed to nonsignificant findings for some of the determinants associated with child overweight status. Another limitation was the recall and social desirability biases in caregivers reporting factors associated with overweight/obesity in young children. The lack of inclusion of variables such as the age child started child care may contribute to understanding of maternal breastfeeding practices, introduction of solid foods, and bottle-feeding worth exploring in future studies. Other limitations of the study included the lack of variables related to child physical activities in the home environment.

The results of our study contribute to the existing literature on socioeconomic, racial, and ethnic disparities in overweight/obesity in young children living in the U.S., especially those living in Hispanic minority-majority communities such as Miami-Dade County. However, our findings may only be applicable to similar metropolitan areas with increased Hispanic composition. Strengths of the study included the representation of 
Hispanics across all income strata, and may represent one of limited studies that examine socioeconomic and racial/ ethnic differences in early feeding, dietary, and sedentary behaviors associated with overweight/ obesity in preschoolers enrolled in child care. Future studies may benefit from the inclusion of child-care-related nutrition, physical activity, and sedentary variables, and more objective measurements of overall variables. Further studies are needed to explore the barriers to early feeding, dietary, and sedentary behaviors, using a large sample of children of various SEP and ethnicities to confirm our findings.

\section{Conclusions}

In this study, we found approximately one-third of preschoolers were overweight/ obese. Middle-SEP groups and Hispanics had the highest prevalence of combined overweight and obesity. The lack of daily consumption of fruits combined with screentime use on weekends present opportunities for prevention programs targeted to parents of preschool children, especially in the Hispanic population and in middle-SEP groups. Our findings have implications for cultural considerations in strategies directed towards better early feeding practices (breastfeeding, early introduction to foods) as well as dietary (fruit, vegetable consumption, sweetened beverages) and sedentary practices in the prevention of overweight/ obesity for ethnic preschool minorities in the home environment. The child care environment may present such opportunities for caregiver outreach and education on preventive measures of childhood overweight/ obesity, especially towards middle-SEP families and Hispanic ethnic minorities. 


\section{References}

1. Ogden CL, Carroll MD, Lawman HG, Fryar CD, Kruszon-Moran D, Kit BK, Flegal KM: Trends in Obesity Prevalence Among Children and Adolescents in the United States, 1988-1994 Through 2013-2014. Jama 2016, 315(21):2292-2299.

2. Lorson BA, Melgar-Quinonez HR, Taylor CA: Correlates of fruit and vegetable intakes in US children. J Am Diet Assoc 2009, 109(3):474-478.

3. Krebs-Smith SM, Cook A, Subar AF, Cleveland L, Friday J, Kahle LL: Fruit and vegetable intakes of children and adolescents in the United States. Archives of pediatrics \& adolescent medicine 1996, 150(1):81-86.

4. Briefel RR, Deming DM, Reidy KC: Parents' Perceptions and Adherence to Children's Diet and Activity Recommendations: the 2008 Feeding Infants and Toddlers Study. Prev Chronic Dis 2015, 12:E159.

5. Perez-Escamilla R, Kac G: Childhood obesity prevention: a life-course framework. International journal of obesity supplements 2013, 3(Suppl 1):S3-s5

6. Mameli C, Mazzantini S, Zuccotti GV: Nutrition in the First 1000 Days: The Origin of Childhood Obesity. Int J Environ Res Public Health 2016, 13(9).

7. Davison KK, Birch LL: Childhood overweight: a contextual model and recommendations for future research. Obes Rev 2001, 2(3):159-171.

8. Freedman DS, Khan LK, Serdula MK, Dietz WH, Srinivasan SR, Berenson GS: The relation of childhood BMI to adult adiposity: the Bogalusa Heart Study. Pediatrics 2005, 115(1):22-27.

9. Nader PR, O'Brien M, Houts R, Bradley R, Belsky J, Crosnoe R, Friedman S, Mei Z, Susman EJ: Identifying risk for obesity in early childhood. Pediatrics 2006, 118(3):e594-601.

10. Freedman DS, Mei Z, Srinivasan SR, Berenson GS, Dietz WH: Cardiovascular risk factors and excess adiposity among overweight children and adolescents: the Bogalusa Heart Study. The Journal of Pediatrics 2007, 150(1):12-17.e12.

11. Franks PW, Hanson RL, Knowler WC, Sievers ML, Bennett PH, Looker HC: Childhood obesity, other cardiovascular risk factors, and premature death. $N$ Engl J Med 2010, 362(6):485-493.

12. Pudrovska T, Logan ES, Richman A: Early-life social origins of later-life body weight: the role of socioeconomic status and health behaviors over the life course. Social science research 2014, 46:59-71. 
13. Parsons TJ, Power C, Logan S, Summerbell CD: Childhood predictors of adult obesity: a systematic review. Int J Obes Relat Metab Disord 1999, 23 Suppl 8:S1107.

14. Starkey L, Revenson TA: Early changes in socioeconomic status do not predict changes in body mass in the first decade of life. Annals of behavioral medicine : a publication of the Society of Behavioral Medicine 2015, 49(2):212-220.

15. Singh GK, Siahpush M, Kogan MD: Rising social inequalities in US childhood obesity, 2003-2007. Ann Epidemiol 2010, 20.

16. Demment MM, Haas JD, Olson CM: Changes in family income status and the development of overweight and obesity from 2 to 15 years: a longitudinal study. BMC Public Health 2014, 14:417.

17. Grimm KA, Foltz JL, Blanck HM, Scanlon KS: Household income disparities in fruit and vegetable consumption by state and territory: results of the 2009 Behavioral Risk Factor Surveillance System. J Acad Nutr Diet 2012, 112(12):2014-2021.

18. Spencer N, Thanh TM, Louise S: Low income/socio-economic status in early childhood and physical health in later childhood/adolescence: a systematic review. Matern Child Health J 2013, 17(3):424-431.

19. May AM, Pan L, Sherry B, Blanck HM, Galuska D, Dalenius K, Polhamus B, Kettel-Khan L, Grummer-Strawn LM: Vital signs: obesity among low-income, preschool-aged children--United States, 2008-2011. In: MMWR Morb Mortal Wkly Rep. Edited by Div of Nutrition PA, and Obesity, National Center for Chronic Disease Prevention and Health Promotion, CDC., vol. 62, 2013/08/09 edn; 2013: 629-634.

20. Banks GG, Berlin KS, Rybak TM, Kamody RC, Cohen R: Disentangling the Longitudinal Relations of Race, Sex, and Socioeconomic Status, for Childhood Body Mass Index Trajectories. Journal of pediatric psychology 2016, 41(4):453461.

21. Zarnowiecki D, Ball K, Parletta N, Dollman J: Describing socioeconomic gradients in children's diets - does the socioeconomic indicator used matter? The international journal of behavioral nutrition and physical activity 2014, 11(1):44.

22. Springer AE, Li L, Ranjit N, Delk J, Mehta K, Kelder SH: School-level economic disadvantage and obesity in middle school children in central Texas, USA: a cross-sectional study. The international journal of behavioral nutrition and physical activity 2015, 12 Suppl 1:S8. 
23. Rothenberg L, Goldhagen S, Harbin V, Forry N: Maryland Child Care Choices Study: Child care decision-making process and child care choices among applicants for temporary cash assistance. In., vol. 2013-28. Bethesda, Maryland: Child Trends; 2013.

24. Lindsay AC, Salkeld JA, Greaney ML, Sands FD: Latino family childcare providers' beliefs, attitudes, and practices related to promotion of healthy behaviors among preschool children: a qualitative study. J Obes 2015, 2015:409742.

25. Taveras EM, Gillman MW, Kleinman KP, Rich-Edwards JW, Rifas-Shiman SL: Reducing racial/ethnic disparities in childhood obesity: the role of early life risk factors. JAMA pediatrics 2013, 167(8):731-738.

26. Moreno-Black G, Stockard J: Two Worlds of Obesity: Ethnic Differences in Child Overweight/Obesity Prevalence and Trajectories. Journal of racial and ethnic health disparities 2016, 3(2):331-339.

27. Park MK, Menard SW, Schoolfield J: Prevalence of overweight in a triethnic pediatric population of San Antonio, Texas. Int J Obes Relat Metab Disord 2001, 25(3):409-416.

28. U.S. Census Bureau. 2016. Quick Facts. Miami City, Florida. Retrieved from [https://www.census.gov/quickfacts/table/ PST045215/1245000,12086]

29. Miami-Dade County Community Health Report Card. Retrieved from [http://www.miamidadematters.org/index.php?module=indicators\&controller=ind ex\&action=dashboard\&id=83017053156222624]

30. State and County Quick Facts. Florida. 2016. Miami-Dade County. Retrieved from [http://quickfacts.census.gov/qfd/states/12000.html]

31. Messiah SE, Asfour L, Arheart KL, Selem SM, Uhlhorn SB, Natale R:

Relationship Between Parent Demographic Characteristics, Perinatal and Early Childhood Behaviors, and Body Mass Index Among Preschool-Age Children. Journal of immigrant and minority health / Center for Minority Public Health 2014.

32. University of California Cooperative Extension. 2017.Healthy Kids Survey. Retrieved from [https://ucdavis.app.box.com/s/ zcqr0e3604obolbuy5l5].

33. Asfour L, Natale R, Uhlhorn S, Arheart KL, Haney K, Messiah SE: Ethnicity, Household Food Security, and Nutrition and Activity Patterns in Families With Preschool Children. J Nutr Educ Behav 2015, 47(6):498-505.e491. 
34. Nihiser AJ, Lee SM, Wechsler H, McKenna M, Odom E, Reinold C, Thompson D, Grummer-Strawn L: Body mass index measurement in schools. J Sch Health 2007, 77(10):651-671; quiz 722-654.

35. Monroe County and Miami-Dade Early Learning Coalition. School readiness. 2016. Retrieved from http://www.elcmdm.org/our_services/SchoolReadiness.html

36. (CON) CoNatCoSMaF: Sports drinks and energy drinks for children and adolescents: are they appropriate? Pediatrics 2011, 127(6):1182-1189.

37. U.S. Department of Agriculture. Food and Nutrition Service (2013). Limit Screen Time. Alexandria, VA. Retrieved from https://www.fns.usda.gov/sites/default/ files/limitscreen.pdf.

38. Pew Research Center. The American Middle Class is losing ground. 2015. Retrieved from http://www.pewsocialtrends.org/2015/12/09/the-american-middleclass-is-losing-ground/

39. Ogden CL, Lamb MM, Carroll MD, Flegal KM: Obesity and socioeconomic status in children and adolescents: United States, 2005-2008. NCHS Data Brief 2010(51):1-8.

40. Pan L, Grummer-Strawn LM, McGuire LC, Park S, Blanck HM: Trends in state/territorial obesity prevalence by race/ethnicity among U.S. low-income, preschool-aged children. Pediatr Obes 2016, 11(5):397-402.

41. Nobari TZ, Wang MC, Chaparro MP, Crespi CM, Koleilat M, Whaley SE: Immigrant enclaves and obesity in preschool-aged children in Los Angeles County. Soc Sci Med 2013, 92:1-8.

42. Hansstein FV: The Impact of Breastfeeding on Early Childhood Obesity: Evidence From the National Survey of Children's Health. Am J Health Promot 2016, 30(4):250-258.

43. Rogers SL, Blissett J: Breastfeeding duration and its relation to weight gain, eating behaviours and positive maternal feeding practices in infancy. Appetite 2016.

44. Geoffroy MC, Power C, Touchette E, Dubois L, Boivin M, Seguin JR, Tremblay RE, Cote SM: Childcare and overweight or obesity over 10 years of follow-up. The Journal of pediatrics 2013, 162(4):753-758.e751.

45. Alberdi G, McNamara AE, Lindsay KL, Scully HA, Horan MH, Gibney ER, McAuliffe FM: The association between childcare and risk of childhood 
overweight and obesity in children aged 5 years and under: a systematic review. Eur J Pediatr 2016, 175(10):1277-1294.

46. Johnson P, Montgomery M, Ewell P: Federal Food Assistance Programs and Cardiovascular Risk Factors in Low-Income Preschool Children. J Community Health 2016, 41(3):626-634.

47. Banfield EC, Liu Y, Davis JS, Chang S, Frazier-Wood AC: Poor Adherence to US Dietary Guidelines for Children and Adolescents in the National Health and Nutrition Examination Survey Population. J Acad Nutr Diet 2016, 116(1):21-27.

48. Wyse R, Campbell E, Nathan N, Wolfenden L: Associations between characteristics of the home food environment and fruit and vegetable intake in preschool children: a cross-sectional study. BMC Public Health 2011, 11:938.

49. Fletcher S, Wright C, Jones A, Parkinson K, Adamson A: Tracking of toddler fruit and vegetable preferences to intake and adiposity later in childhood. Maternal \& child nutrition 2016.

50. Wosje KS, Khoury PR, Claytor RP, Copeland KA, Hornung RW, Daniels SR, Kalkwarf HJ: Dietary patterns associated with fat and bone mass in young children. The American journal of clinical nutrition 2010, 92(2):294-303.

51. Korenman S, Abner KS, Kaestner R, Gordon RA: The Child and Adult Care Food Program and the Nutrition of Preschoolers. Early Child Res Q 2013, 28(2):325336.

52. Zhang G, Wu L, Zhou L, Lu W, Mao C: Television watching and risk of childhood obesity: a meta-analysis. Eur J Public Health 2016, 26(1):13-18.

53. Hu, F. B. (2013). Resolved: there is sufficient scientific evidence that decreasing sugar-sweetened beverage consumption will reduce the prevalence of obesity and obesity-related diseases. Obes Rev, 14(8), 606-619. doi:10.1111/obr.12040

54. Vorwerg Y, Petroff D, Kiess W, Bluher S: Physical activity in 3-6 year old children measured by SenseWear Pro(R): direct accelerometry in the course of the week and relation to weight status, media consumption, and socioeconomic factors. PloS one 2013, 8(4):e60619.

55. Chuang, R. J., Sharma, S., Skala, K., \& Evans, A. (2013). Ethnic differences in the home environment and physical activity behaviors among low-income, minority preschoolers in Texas. Am J Health Promot, 27(4), 270-278. doi:10.4278/ajhp.110427-QUAN-171 
56. Dennison BA, Erb TA, Jenkins PL: Television viewing and television in bedroom associated with overweight risk among low-income preschool children. Pediatrics 2002, 109(6):1028-1035.

57. Cespedes EM, Gillman MW, Kleinman K, Rifas-Shiman SL, Redline S, Taveras EM: Television viewing, bedroom television, and sleep duration from infancy to mid-childhood. Pediatrics 2014, 133(5):e1163-1171.

58. Shrewsbury V, Wardle J. Socioeconomic status and adiposity in childhood: a systematic review of cross-sectional studies 1990-2005. Obesity (Silver Spring) 2008;16.

59. Johnson P, Montgomery M, Ewell P. Federal Food Assistance Programs and Cardiovascular Risk Factors in Low-Income Preschool Children. J Community Health 2016;41:626-34.

60. Geoffroy MC, Power C, Touchette E, et al. Childcare and overweight or obesity over 10 years of follow-up. The Journal of pediatrics 2013;162:753-8.e1.

61. Anderson SE, Whitaker RC. Prevalence of obesity among US preschool children in different racial and ethnic groups. Archives of pediatrics \& adolescent medicine 2009;163:344-8.

62. Pan L, Grummer-Strawn LM, McGuire LC, Park S, Blanck HM. Trends in state/territorial obesity prevalence by race/ethnicity among U.S. low-income, preschool-aged children. Pediatr Obes 2016;11:397-402.

63. Weedn AE, Hale JJ, Thompson DM, Darden PM. Trends in obesity prevalence and disparities among low-income children in Oklahoma, 2005-2010. Child Obes 2014;10:318-25.

64. Delavari M, Sonderlund AL, Swinburn B, Mellor D, Renzaho A. Acculturation and obesity among migrant populations in high income countries--a systematic review. BMC Public Health 2013;13:458.

65. Kim J, Peterson KE. Association of infant child care with infant feeding practices and weight gain among US infants. Archives of pediatrics \& adolescent medicine 2008;162:627-33.

66. Singh GK, Kogan MD, Dee DL. Nativity/immigrant status, race/ethnicity, and socioeconomic determinants of breastfeeding initiation and duration in the United States, 2003. Pediatrics 2007;119 Suppl 1:S38-46. 
67. Woo Baidal JA, Locks LM, Cheng ER, Blake-Lamb TL, Perkins ME, Taveras EM. Risk Factors for Childhood Obesity in the First 1,000 Days: A Systematic Review. Am J Prev Med 2016;50:761-79.

68. Lind JN, Perrine CG, Li R, Scanlon KS, Grummer-Strawn LM. Racial disparities in access to maternity care practices that support breastfeeding - United States, 2011. MMWR Morb Mortal Wkly Rep 2014;63:725-8.

69. Di Noia J, Monica D, Cullen KW, Perez-Escamilla R, Gray HL, Sikorskii A. Differences in Fruit and Vegetable Intake by Race/Ethnicity and by Hispanic Origin and Nativity Among Women in the Special Supplemental Nutrition Program for Women, Infants, and Children, 2015. Prev Chronic Dis 2016;13:E115.

70. Asfour L, Natale R, Uhlhorn S, Arheart KL, Haney K, Messiah SE. Ethnicity, Household Food Security, and Nutrition and Activity Patterns in Families With Preschool Children. J Nutr Educ Behav 2015;47:498-505 e1.

71. Wyse R, Campbell E, Nathan N, Wolfenden L. Associations between characteristics of the home food environment and fruit and vegetable intake in preschool children: a cross-sectional study. BMC Public Health 2011;11:938.

72. Lovasi GS, Schwartz-Soicher O, Quinn JW, et al. Neighborhood safety and green space as predictors of obesity among preschool children from low-income families in New York City. Prev Med 2013;57:189-93. 
Table 1. Child characteristics, dietary, and sedentary factors by weight status

\begin{tabular}{|c|c|c|c|}
\hline & $\begin{array}{c}\text { Total Sample } \\
(\mathrm{n}=366)\end{array}$ & $\begin{array}{l}\text { Normal weight } \\
\quad(n=257)\end{array}$ & $\begin{array}{l}\text { Overweight/obese } \\
(\mathrm{n}=109)\end{array}$ \\
\hline Characteristic & n (\%) & n (\%) & n (\%) \\
\hline \multicolumn{4}{|l|}{ Race/ethnicity* } \\
\hline NH White & 38 (10.6) & $30(78.9)$ & $8(21.1)$ \\
\hline NH Black & $62(17.2)$ & $51(82.3)$ & $11(17.7)$ \\
\hline Hispanic & $241(66.9)$ & $157(65.1)$ & $84(34.6)$ \\
\hline Other & $19(5.3)$ & $14(73.7)$ & $5(26.3)$ \\
\hline \multicolumn{4}{|l|}{ SEP } \\
\hline Low & $159(43.4)$ & 117(73.6) & $42(26.4)$ \\
\hline Middle & 133(36.3) & $86(64.7)$ & $47(35.3)$ \\
\hline High & $74(20.2)$ & $54(73.0)$ & $20(27.0)$ \\
\hline \multicolumn{4}{|c|}{ Caregiver country of birth } \\
\hline U.S. & 189(52.1) & 136(72.0) & $53(28.0)$ \\
\hline Non-U.S. & $174(47.9)$ & $118(67.8)$ & $56(32.2)$ \\
\hline \multicolumn{4}{|l|}{ Free/reduced child care } \\
\hline Yes & $129(37.4)$ & $98(76.0)$ & $31(24.0)$ \\
\hline No & $174(47.9)$ & $118(67.8)$ & $56(32.2)$ \\
\hline \multicolumn{4}{|l|}{ Caregiver education } \\
\hline High school or less & $79(21.6)$ & $58(73.4)$ & 21(26.6) \\
\hline Some college & $79(21.6)$ & $53(67.1)$ & $26(32.9)$ \\
\hline Associate or higher & 191(52.2) & $136(71.2)$ & $55(28.8)$ \\
\hline \multicolumn{4}{|l|}{ Early Feeding } \\
\hline \multicolumn{4}{|l|}{ Breastfed } \\
\hline Yes & $227(70.0)$ & $155(68.3)$ & 72(31.7) \\
\hline No & 97 (29.9) & 73 (75.3) & $24(24.7)$ \\
\hline \multicolumn{4}{|l|}{ Duration bottle-feeding } \\
\hline$<6$ months & 285 (97.9) & $194(68.2)$ & $91(31.8)$ \\
\hline$>7$ months & $6(2.1)$ & $5(83.3)$ & $1(16.7)$ \\
\hline \multicolumn{4}{|l|}{ Duration breastfeeding } \\
\hline$\leq 6$ months & $145(65.0)$ & $100(69.0)$ & $45(31.0)$ \\
\hline > 7 month & $78(35.0)$ & $50(64.1)$ & 28 (35.9) \\
\hline \multicolumn{4}{|l|}{ Introduction solid foods } \\
\hline$\leq 6$ months & $155(49.1)$ & 104(67.1) & 51(32.9) \\
\hline$>7$ months & 161(50.9) & $111(68.9)$ & $50(31.1)$ \\
\hline \multicolumn{4}{|l|}{ Dietary behaviors } \\
\hline \multicolumn{4}{|l|}{ Fruits * } \\
\hline Daily & 109 (43.6) & $83(76.1)$ & $26(23.9)$ \\
\hline Not daily & $141(56.4)$ & $91(64.5)$ & $50(35.5)$ \\
\hline \multicolumn{4}{|l|}{ Vegetables } \\
\hline Daily & $62(28.6)$ & $48(77.4)$ & $14(22.6)$ \\
\hline Not daily & $155(71.4)$ & $103(66.5)$ & $52(33.5)$ \\
\hline \multicolumn{4}{|l|}{ Fruit/ sport drinks } \\
\hline Yes & 251(74.3) & $176(70.1)$ & 75(29.9) \\
\hline No & $87(25.7)$ & $60(69.0)$ & $27(31.0)$ \\
\hline \multicolumn{4}{|l|}{ Soda with meals } \\
\hline Yes & 108 (31.9) & $73(67.2)$ & $35(32.4)$ \\
\hline No & $231(68.1)$ & $164(71.0)$ & $67(68.1)$ \\
\hline
\end{tabular}




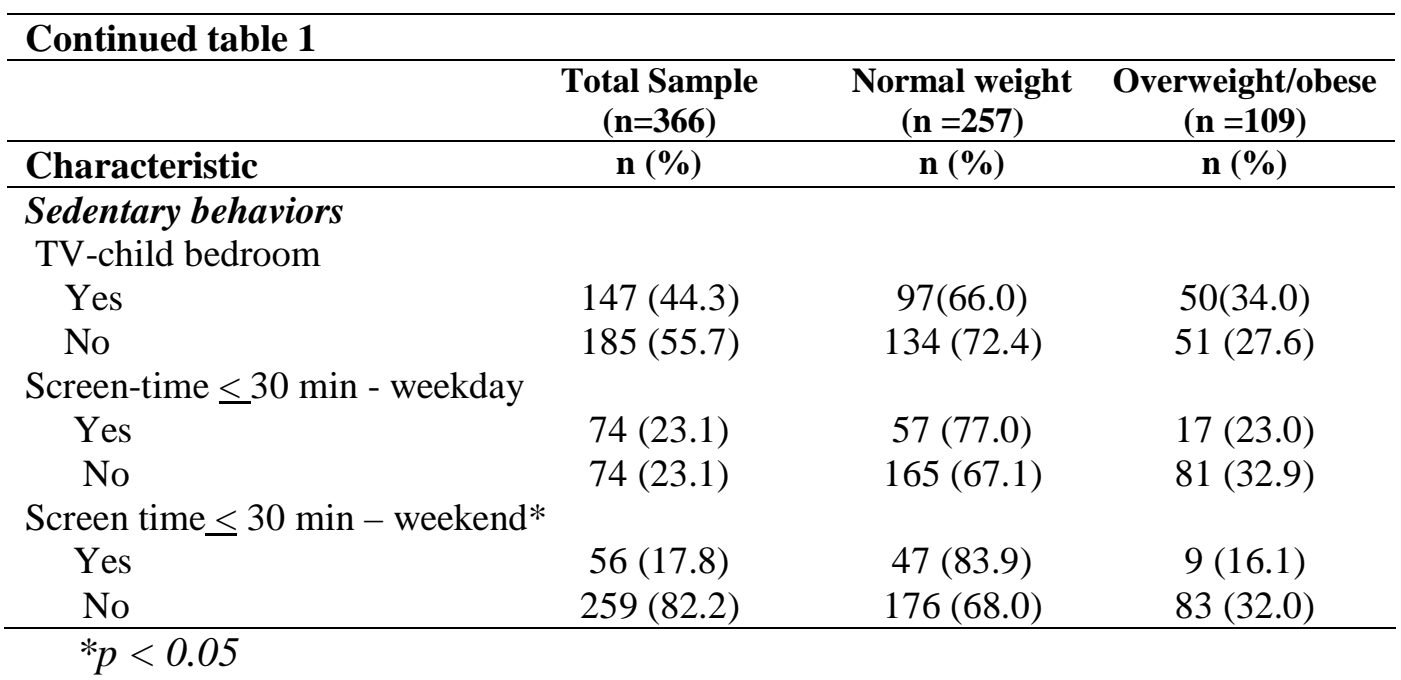




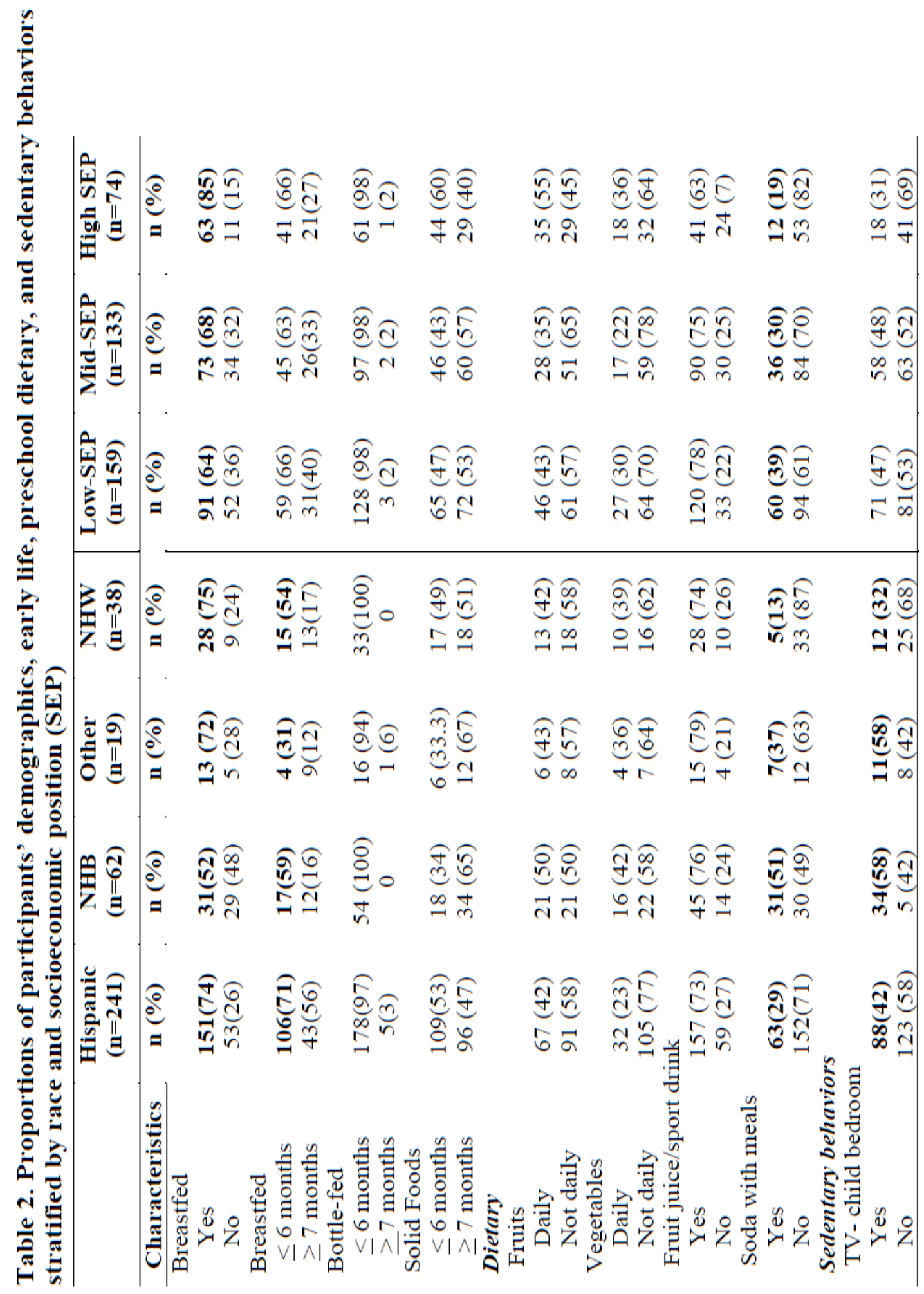




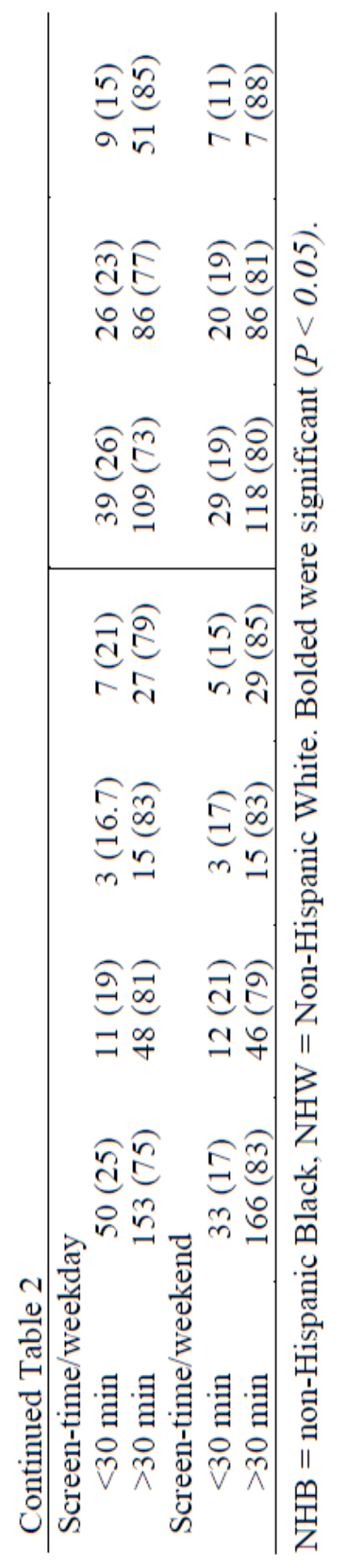


Table 3. Factors associated with child weight status on logistic regression models

\begin{tabular}{|c|c|c|c|}
\hline Characteristics & $\begin{array}{l}\text { Model } 1 \\
(95 \% \text { CI })\end{array}$ & $\begin{array}{l}\text { Model } 2 \\
(95 \% \text { CI })\end{array}$ & $\begin{array}{l}\text { Model } 3 \\
(95 \% \text { CI })\end{array}$ \\
\hline \multicolumn{4}{|l|}{ Screen-time } \\
\hline$<30$ min weekends & $.35(.11,1.09)$ & $.33(.11,1.03)$ & $.34(.11,1.07)$ \\
\hline \multicolumn{4}{|l|}{ Fruits } \\
\hline Not daily & $1.58(.75,3.35)$ & $2.04(1.05,3.97)$ & $2.26(1.13,4.52)$ \\
\hline Daily & Ref & Ref & Ref \\
\hline \multicolumn{4}{|l|}{ Vegetables } \\
\hline Not daily & $1.72(.71,4.20)$ & & \\
\hline Daily & Ref & & \\
\hline \multicolumn{4}{|l|}{ Breastfed } \\
\hline No & $1.26(.612,2.61)$ & & \\
\hline Yes & Ref & & \\
\hline \multicolumn{4}{|c|}{ Model 1: logistic regression analysis, unadjusted for covariates (age, gender, SEP, ethnicity). } \\
\hline \multicolumn{4}{|c|}{$\begin{array}{l}\text { Model 2: Backward stepwise elimination (breastfeeding, daily vegetable, screen-time on weekday } \\
\text { eliminated). Controlled for age, gender, and SEP }\end{array}$} \\
\hline \multicolumn{4}{|c|}{ Model 3: Controlled for age, gender, SEP, and ethnicity. } \\
\hline
\end{tabular}


Table 4. Factors associated with child overweight in Hispanic preschoolers on multiple logistic regression model using backward stepwise elimination

\begin{tabular}{llll}
\hline Variables* & AOR & (95\% CI) & $P$ \\
\hline $\begin{array}{l}\text { Screen-time } \\
<30 \text { min weekend }\end{array}$ & .34 & .11 to 1.08 & .066 \\
$\begin{array}{l}\text { Fruit intake } \\
\quad \text { Not daily }\end{array}$ & $\mathbf{2 . 2 3}$ & 1.12 to 4.45 & .023 \\
$\quad$ Daily & Ref & & \\
Ethnicity & & & \\
$\quad$ Hispanic & $\mathbf{2 . 9 1}$ & 1.36 to 6.21 & .006 \\
$\quad$ Non-Hispanic & Ref & & \\
\hline
\end{tabular}

*Breastfeeding and daily vegetable consumption eliminated were non-significant. Model controlled for age, gender, and SEP. 


\section{CONCLUSIONS}

This dissertation conceptualizes the role of the neighborhood social and physical factors as well as organizational, household and/or individual factors as mediators of the correlation between residential segregation and obesity in Hispanic preschoolers. A new model is presented as a strategy to guide in the specification of factors in testable analytical models of racial residential segregation and obesity in Hispanic preschool children early in the life course. The model also has implications for other ethnic and migrant minorities living in ethnic enclaves in the United States. Findings in the context of racial residential segregation show that while segregated residential areas may be affected by adverse environments limited to physical activity or access to healthy foods, they may represent supportive environments particularly for new immigrants through the social networks, common languages, practices, and norms.

This is the first study to examine child care centers’ adherence to legislative changes in nutritional, physical activity, and screen time practices in Miami-Dade County. Low- and middle-SEP centers fared better in their adherence to nutrition regulations, especially the serving of low/ fat-free milk and whole fruits, when compared to high-SEP centers. Serving of vegetables was lower compared to serving of fruits in low- and middle-SEP centers. High-SEP centers were lacking the most in serving of vegetables during meals and snacks. All low- and middle-SEP centers served meals and snacks, and almost all of them were CACFP participants. Our findings have implications for continued work in the in the practice and policy arena to better align child care center nutrition, physical activity, and screen-time practices with national standards. 
This research provides the first evidence that middle-SEP children are experiencing increasing overweight rates, especially in minority majority populated areas such as Miami-Dade County. Approximately one-third of preschoolers were classified as overweight/ obese. Hispanics as the minority-majority in this sample had the highest prevalence of overweight/ obesity. Early feeding factors, such as shorter duration of breastfeeding and early introduction to solid foods within the first six months of life, when combined with the low consumption of fruits and vegetables, and increased sedentary behaviors present opportunities for future work with parents and child care providers of children enrolled in child care. The racial and ethnic differences in the determinants suggest the need for cultural considerations in strategies directed towards nutrition, physical activity, and sedentary practices to prevent overweight/ obesity for ethnic preschool minorities. The increasing prevalence of overweight in all socioeconomic groups suggest that the research efforts should be expanded beyond lowincome groups. 


\section{APPENDICES}

\section{Appendix 1. Questions that were used to obtain information from caregivers about preschoolers' dietary and screen-time habits}

For each question, mark your response $(\checkmark)$ or write your response in the space provided.

\section{Parent/Guardian Information}

1. What is your age?

2. What is your gender?

Male

Female

3. What country were you born in?

4. How long have you lived in the United States? years or months (if less than one year)

5. What is your preferred language? ( $\checkmark$ check one)
English
Spanish
Creole
Other

6. How well would you say you speak English? ( $\checkmark$ check one)
_ Very Well
Well
Not well
Not at all

7. What is the highest level of education you completed? ( $\checkmark$ check one)

Less than High School
High School diploma/GED
Some College

A__ Associate's Degree
Bachelor's Degree
Graduate Degree

\section{Child Information}

8. What is your relationship to this child? ( $\checkmark$ check one)

_ Mother _Father $\quad$ Step-mother _ Step-father _ Grandmother

9. Are you this child's primary caregiver? ( $\checkmark$ check one)

10. This child is a:

_Boy_Girl

11. What is this child's birth date? (Month):

(Day):

(Year):

12. What is this child's race? ( $\checkmark$ check one or all that apply)

White

$$
\text { Asian }
$$

Pacific Islander Other (please specify):
Black/African American American Indian/Alaskan Native Multi-racial 
13. What is this child's ethnic group? ( $\checkmark$ check one)

$\begin{array}{ll}\text { _Hispanic/Black } & \text { Non-Hispanic Black } \\ \text { Hispanic/Cuban } & \text { Non-Hispanic White } \\ \text { Hispanic/Mexican } & \text { Haitian } \\ \text { Hispanic/Puerto Rican } & \text { Other Caribbean Islander } \\ \text { Hispanic/Other (please specify): } & \\ \text { Non-Hispanic Other (please specify): }\end{array}$

14. What country was this child born in?

15. How much did this child weigh at birth? Pounds:

ounces:

16. Was this child full-term or pre-term? ( $\checkmark$ check one)

Full Term

Pre-Term (less than 37 weeks gestational age)

Don't Know

17. What languages are spoken in this child's home? ( $\checkmark$ check all that apply)

English _ Spanish_Creole__ Other (specify):

18. What language is spoken in this child's home most often? ( $\checkmark$ check one)

_English _ Spanish__reole _ _ Other (specify):

19. What is this child's preferred language? ( $\checkmark$ check one)

_English _ Spanish_Creole _ _ Other (specify):

20. Do you receive free or reduced-cost childcare or does your child qualify for the 'School Readiness' program?

Y Yes N No

21. Was this child breastfed? __Yes _ _No

21b. If yes, how long was this child breastfed? weeks / months (circle one)

21c. Are you still breast feeding? _Yes_No

22. Was this child fed infant formula? __Yes _ No

23. At what age did this child stop using the bottle? months / years (circle one) Still uses

24. At what age did this child start eating solid foods? months / years (circle one) 
25. Did this child use a pacifier or thumb sucking? ( $\checkmark$ check all that apply)

__Pacifier__ _ Thumb Sucking _ Neither

If yes to either, at what age did the child stop using it?

25b. Age stopped using the pacifier months / years (circle one) or still using $(\checkmark)$

25c. Age stopped thumb sucking: months / years (circle one) or still using $(\checkmark)$

26. Does your child eat fruit?

_No _ Sometimes__ Often _Everyday

27. Does your child eat vegetables?

_No _ Sometimes _Often _ Everyday

28. Does your child drink milk? ___No ___ Sometimes __ Often
Every day $\rightarrow$ \# times a day

29. What kind of milk does your child drink?

_Whole milk__ $2 \%$ milk__ $1 \%$ milk Flavored milk (chocolate or other) Skim/Nonfat milk Other:

30. Does your child drink fruit drinks, sport drinks or punch?

__No __ Sometimes _ Often _Everyday

31. Does your child drink soda?

No Sometimes __ Often Everyday

32. On a typical week day, how much time is spent watching television, watching DVDs or videos, playing computer games, games consoles or on smart phone/tablet apps?

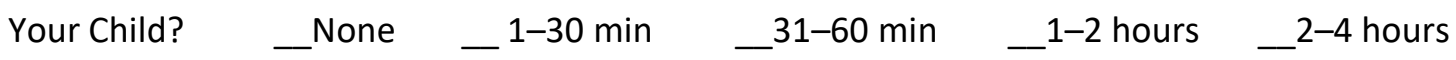
_more than 4 hours

33. On a typical weekend day, how much time is spent watching television, watching DVDs or videos, playing computer games, games consoles or on smart phone/tablet apps?

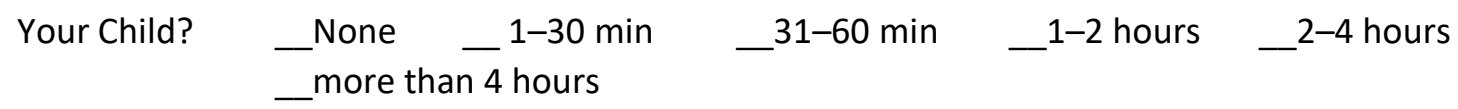

34. Does your child have a TV in his/her bedroom or access to other screen-time device in the bedroom?

Yes No 
35. Does your child eat meals while watching TV?

_No _ _ Some days _ Most days _Everyday 
VITA

CATHERINA CHANG MARTINEZ

I. Higher Education

1989- 1992

Associate in Science in Nursing

Miami-Dade Community College

Miami, Florida

$1993-2001$

Mount Sinai Medical Center

Nurse Educator / Clinical Staff Nurse

Medical-surgical unit /Critical Care Unit

1994 - 1996

Bachelor of Science in Nursing

Florida International University

Miami, Florida

$1996-2000$

Master of Science in Nursing

Nurse Practitioner Program

Florida International University

Miami, Florida

$2002-2005$

Jackson Memorial Hospital

Nurse Practitioner/ Coordinator Acute

Pain Services

2005 - 2013

Cleveland Clinic Florida

Director of Telemetry Department/

Intermediate Care Unit/

2017 - Present

Doctoral Candidate

Florida International University

Miami, Florida. 
PUBLICATIONS

1. Chang-Martinez, C., Ahmed, N.U., Natale, R.A. (2016). Residential segregation, neighborhood social and physical context in obesity disparities in Hispanic preschoolers: a conceptual model. Manuscript in press.

2. Chang-Martinez, C. (2015). Long-Term Medication Adherence in Acute Coronary Syndrome Survivors: Exploring Underlying Factors -

Corresponding Letter. Heart Lung; 44(4):366. doi: 10.1016/j.hrtlng.2015.04.002. Epub 2015 May 16.

3. Chang-Martinez, C. (2015). Racial and ethnic-related differences in obesity and the migration factor - Corresponding Letter. Cadernos de Saude Publica; 31(7): 1571. doi: 10.1590/0102-311XCA010715.

4. Natale, R., Chang, C., Messiah, S. Obesity Prevention in Young Children. In S. Ahmad, \& S. Imam (Eds.), Obesity- A Practical Guide. Springer, USA/Switzerland, in press.

5. Chang-Martinez, C. (2013). Book Review: Educational Gerontology, 39: 11, 865866, doi: 10.1080/03601277.2013.818905

6. Ugarriza, D.N., Brown, S.E., Chang-Martinez, C. (2007). Anglo-American mothers and the prevention of postpartum depression. Issues in Mental Health Nursing, 28(7), 781-798.

7. Walsh, S.M., Chang, C.Y., Schmidt, L.A., \& Yoepp, J.H. (2005). Lowering stress while teaching research: a creative arts intervention in the classroom. Journal of Nursing Education, 44(7), 330-333. 